\title{
Physiological, Biochemical, and Transcriptomic Responses of Neolamarckia cadamba to Aluminum Stress
}

\author{
Baojia Dai ${ }^{1,2}$, Chen Chen $\left.{ }^{1,2}{ }^{(}\right)$, Yi Liu ${ }^{1,2}$, Lijun Liu ${ }^{3}$, Mirza Faisal Qaseem ${ }^{1,2}{ }^{(0)}$, \\ Jinxiang Wang ${ }^{4,5}$, Huiling $\mathrm{Li}^{1,2, *}$ and $\mathrm{Ai}-\mathrm{Min} \mathrm{Wu}^{1,2,5, *}$ \\ 1 State Key Laboratory for Conservation and Utilization of Subtropical Agro-Bioresources, \\ Guangdong Key Laboratory for Innovative Development and Utilization of Forest Plant Germplasm, \\ College of Forestry and Landscape Architecture, South China Agricultural University, \\ Guangzhou 510642, China; baojiadai@outlook.com (B.D.); cc@cch3n.cn (C.C.); yiyiliuliu@outlook.com (Y.L.); \\ faisal.ali522@gmail.com (M.F.Q.) \\ 2 Guangdong Key Laboratory for Innovative Development and Utilization of Forest Plant Germplasm, \\ College of Forestry and Landscape Architectures, South China Agricultural University, \\ Guangzhou 510642, China \\ 3 State Forestry and Grassland Administration Key Laboratory of Silviculture in Downstream Areas of the \\ Yellow River, College of Forestry, Shandong Agriculture University, Taian 271018, China; \\ lijunliu@sdau.edu.cn \\ 4 Root Biology Center \& College of Natural Resources and Environment, South China Agricultural University, \\ Guangzhou 510642, China; jinxwang@scau.edu.cn \\ 5 Guangdong Laboratory of Lingnan Modern Agriculture, Guangzhou 510642, China \\ * Correspondence: lihl@scau.edu.cn (H.L.); wuaimin@scau.edu.cn (A.-M.W.)
}

Received: 12 November 2020; Accepted: 8 December 2020; Published: 17 December 2020

\begin{abstract}
Aluminum is the most abundant metal of the Earth's crust accounting for 7\% of its mass, and release of toxic $\mathrm{Al}^{3+}$ in acid soils restricts plant growth. Neolamarckia cadamba, a fast-growing tree, only grows in tropical regions with acidic soils. In this study, N. cadamba was treated with high concentrations of aluminum under acidic condition ( $\mathrm{pH} 4.5)$ to study its physiological, biochemical, and molecular response mechanisms against high aluminum stress. High aluminum concentration resulted in significant inhibition of root growth with time in N. cadamba. The concentration of $\mathrm{Al}^{3+}$ ions in the root tip increased significantly and the distribution of absorbed $\mathrm{Al}^{3+}$ was observed in the root tip after $\mathrm{Al}$ stress. Meanwhile, the concentration of $\mathrm{Ca}, \mathrm{Mg}, \mathrm{Mn}$, and Fe was significantly decreased, but $\mathrm{P}$ concentration increased. Aluminum stress increased activities of antioxidant enzymes such as superoxide dismutase (SOD), catalase from micrococcus lysodeiktic (CAT), and peroxidase (POD) in the root tip, while the content of MDA was decreased. Transcriptome analysis showed 37,478 differential expression genes (DEGs) and 4096 GOs terms significantly associated with treatments. The expression of genes regulating aluminum transport and abscisic acid synthesis was significantly upregulated; however, the genes involved in auxin synthesis were downregulated. Of note, the transcripts of several key enzymes affecting lignin monomer synthesis in phenylalanine pathway were upregulated. Our results shed light on the physiological and molecular mechanisms of aluminum stress tolerance in N. cadamba.
\end{abstract}

Keywords: Neolamarckia cadamba; aluminum stress; signal transduction; hormone; ROS; DEGs

\section{Introduction}

Aluminum is the third most abundant element followed by oxygen and silicon, and constitutes about $7 \%$ of shell mass [1]. The silicate and oxides of aluminum occurring in nature are nontoxic 
to plants; however, $\mathrm{Al}^{3+}$ ions released in acid soils are toxic to plant growth and development [2]. Acid soils account for 30-40\% of the world's arable land [3], accordingly aluminum toxicity has become an important limiting factor for crop growth and yield in acid soils [4-6]. Under acidic conditions, aluminum stress affects the physiological and molecular mechanisms of plants in many ways. The common phenomenon of aluminum toxicity on most plants is the inhibition of root growth [7-9], especially in distal transition zone of the root (DTZ) (1-2 mm) and elongation root zones (3-5 mm) from the root tip [10,11]. Furthermore, it also affects cell wall structure [12], as well as the physical and composition properties, osmotic kinetics, and structure of plasma membrane $[13,14]$. In addition, aluminum stress affects uptake of $\mathrm{Ca}^{2+}$ and other ions [15], results in oxidative stress [16,17], alters hormonal levels, initiates signal transduction [18], and changes cytoskeleton dynamics [19].

At cellular level, Al stress results in an imbalance of reactive oxygen species (ROS) [20-22], which induces changes in activities of protein kinases and transporters and affects the regulation of organic acid secretion and hormonal levels [23,24]. Importantly, aluminum stress can result in membrane lipid peroxidation, DNA damage, pigment degradation, cell wall thickening, and so on [25].

The cell wall is the outermost layer of the plant cell and is the first target of $\mathrm{Al}^{3+}$, and about $99 \%$ of the $\mathrm{Al}^{3+}$ absorbed by plants is deposited in the cell wall and cytosol $[12,26,27]$, while the cell wall of the primary root (PR) mainly consists of pectin, cellulose, hemicellulose, polysaccharide, and protein [28-30]. In the cell wall of the PR, high $\mathrm{Al}^{3+}$ interferes with the binding of $\mathrm{Ca}^{2+}$ with cell wall pectin, affecting the pectin structures and the degradation of cell wall polysaccharides; thus, altering secondary cell wall structure and thickening the cell wall [31,32]. For example, xylan endoglucanase/hydrolase (XTH) and xylanase (XET), involved in xylan degradation, are limited by Al stress [26,33-35]. Likewise, pectin methyl esterase (PME) activity decreased and pectin was highly methylated in aluminum stressed rice [26,36], resulting in cell wall remodeling [37]. Aluminum toxicity also alters the contents of cell wall polysaccharides, for instance, aluminum stress in rice forces the Al rhizotoxicity1 complex (OsSTAR1) and rhizotoxicity2 (OsSTAR2) to transport UDP-glucose to the cell wall in the form of a bacterial-type ATP binding cassette (ABC) transporter to affect the cell wall structure [38]. Several studies have shown that aluminum affects the lignin content $[39,40]$, which affects flexibility of cell wall. Of note, phenylalanine ammonia-lyase (PAL), 4-coumarate:CoA ligase (4CL), cinnamoyl-CoA reductase (CCR), caffeic acid $O$-methyltransferase (COMT), and cinnamyl alcohol dehydrogenase (CAD) are several key enzymes for the synthesis of lignin monomers from phenylalanine [41].

After entering the root tip cell wall, $\mathrm{Al}^{3+}$ interacts with anions on the plasma membrane surface to change the membrane potential and plasma membrane structure, thus changing the activities of ion transporters [42]. For example, a large number of $\mathrm{Al}^{3+}$ ions block the $\mathrm{Ca}^{2+}$ channel, resulting in a negative correlation between $\mathrm{Al}^{3+}$ and $\mathrm{Ca}^{2+}$ in calmodulin activity and other physiological activities [43], and competes with other cations for the binding sites on the surface of the membrane $[44,45]$.

$\mathrm{Al}^{3+}$ is transported into cells either by the apoplastic or symplastic pathway and acts on organelles such as the nucleus, chloroplast, mitochondria, vacuoles, and lysosomes to induce aluminum tolerance genes, such as WRKY, MYB (v-myb avian myeloblastosis viral oncogene homolog), and bZIP (endosperm-specific basic Leu zipper) family genes, and induce transcription factors such as ERF (ethylene-responsive element binding factors), HSF (heat shock transcription factor), ARF (auxin response factor), NF-Y (nuclear factor Y), and the NAC (NAM, ATAF, and CUC) family [46-49], thus regulating their downstream gene expression [50]. For example, oxidative signal inducible 1 (OXI1) kinase mediates oxidative burst signal transduction to diverse downstream responses [51], glutathione S-transferases (GST) expression in Arabidopsis thaliana in response to oxidative stress, etc. [52]. Ferric chelate reductase 2 (FRO2) is an enzyme mediating the accumulation of reactive oxygen species [53]. In addition, NAC transcription factors are mainly involved in the process of senescence and apoptosis controlled by time evolutionary networks, and ANAC090 with ANAC017 plays a major regulatory role in salicylic acid SA and reactive oxygen species (ROS) responses [54,55]. Plants exposed to aluminum stress experience changes in the activities of superoxide dismutase (SOD), catalase from micrococcus lysodeiktic (CAT), malondialdehyde (MDA), peroxidase (POD), and other enzymes $[16,20,56]$, which 
are closely related to the expression of genes involved in oxidative stress regulation. Some studies have shown that auxin influx OsAUX3-2 regulates root development [57], AtPIN3-shaped external current carriers mediate the transport of auxin [58,59], while the overexpression of OsPIN2, an auxin transporter gene, can reduce the production of aluminum-activated ROS [60]. HSF responds to abiotic stress as stress-induced and DNA-binding transcription factors. ERF is an ethylene-responsive factor involved in the regulation of plant hormones proteins regulate peroxidase [61]; the expression of these genes may be regulators of plant response to abiotic stress

The alterations in the cell membrane transport system are induced by altered expression of genes related to various element transporters, e.g., Al-induced secretion of malate (ALMT), multidrug and toxic compound extrusion (MATE) family, a bacterial-type ATP binding cassette (ABC) transporter, the zinc-finger protein (ZAT), and many others disturb the intracellular homeostasis of $\mathrm{Al}$ [38,62-65]. Studies have shown that external chelating and internal detoxification mechanisms are essential for tolerance against aluminum toxicity in higher plants $[66,67]$. The MATE family reduces aluminum toxicity via by chelating external $\mathrm{Al}^{3+}$ by regulating the activation and release of organic acids (citric acid, malic acid, and oxalic acid) to chelate external $\mathrm{Al}$ anions in roots [54,68], e.g., the mutation of WRKY46 results in downregulation of ALMT1 in Arabidopsis subjected to Al stress [69], while in Sorghum bicolor (L.) Moench, SbWRKY1 and DHHC type zinc finger transcription factor 1 (SbZNF1) trans-activated SbMATE [70]. ALMT1 and MATE1 mediate the exudation of malic acid and citric acid anions in wheat, soybean, and other crops [54,71,72]. The internal detoxification mechanism includes the regulation of $\mathrm{Al}^{3+}$ resistance transcription factor 1 (ART1) with downstream aluminum tolerance gene OsALS1 (tonoplast-localized Al transporter) [63,73] and sensitive to proton rhizotoxicity 1 in Arabidopsis (AtSTOP1) with downstream aluminum tolerance gene AtALS3. The expression of AtALMT1 and AtMATE1 [74-76] causes $\mathrm{Al}^{3+}$ to be blocked in vacuoles, while AtALS3 encodes ABC transporter [74], which makes $\mathrm{Al}^{3+}$ chelate with organic acid anions to form a stable and non-toxic complex to reduce aluminum absorption [75]. The heavy metal-associated isoprenylated plant protein 26 (HIPP26) may be involved in heavy metal transport [77,78]; this may also play a role in the process of aluminum stress.

Neolamarckia cadamba (Roxb.) Bosser is a large tree of the Neolamarckia subfamily of Rubiaceae. It belongs to tropical and subtropical tree species [79] and is mainly distributed in Guangdong, Guangxi, Yunnan, and other tropic regions in China and South Asia. It is a deep-rooted fast-growing tree species [80]. It has been widely planted and utilized due to its fast-growing, excellent wood properties, antibacterial, and anti-inflammatory effects. Red and yellow soil in southern China have the strongest acidity [81], so aluminum toxicity will affect the growth of N. cadamba, but the response mechanism of $N$. cadamba to aluminum toxicity has not been well studied, especially at physiological and molecular level. Therefore, in this study, we revealed the physiology and transcriptome responses of N. cadamba to aluminum stress and identified many differential expression genes (DEGs)

\section{Results}

\subsection{Effects of Different Concentrations of $\mathrm{AlCl}_{3}$ on Growth of N. cadamba}

Plant responses to $\mathrm{AlCl}_{3}$ stress differ with severity, tissue type, and duration of exposure. The response of $N$. cadamba to five different concentrations of $\mathrm{AlCl}_{3}$, i.e., $0 \mu \mathrm{M}(\mathrm{CK}), 50 \mu \mathrm{M}, 100 \mu \mathrm{M}$, $200 \mathrm{Mm}$ and $400 \mu \mathrm{M}$, was studied. Although no obvious changes in plant height and leaf growth were observed after 24 days of $\mathrm{Al}$ treatment, significant inhibition of root growth was recorded with increasing concentration of $\mathrm{AlCl}_{3}$ (Figure 1A). The root growth at $50 \mu \mathrm{M} \mathrm{AlCl}$ had no obvious difference when compared to $0 \mu \mathrm{M}(\mathrm{CK}$, no $\mathrm{Al})$ treatment. While the length of primary root (PR) at $400 \mu \mathrm{M} \mathrm{AlCl}$ for 4 days was $0.13 \mathrm{~cm}$, that at $0 \mu \mathrm{M}(\mathrm{CK})$ reached $0.7 \mathrm{~cm}$ (Figure 1B). The inhibition percentage of PR under $400 \mu \mathrm{M} \mathrm{AlCl}_{3}$ treatment at 4 days and 7 days was $13.4 \%$ and $63 \%$, respectively. After 7 days, the root net-growth tended to grow steadily. There was a non-significant effect of different $\mathrm{Al}$ concentrations on plant height as it changed from $6.6 \mathrm{~cm}(\mathrm{CK})$ to $6.1 \mathrm{~cm}\left(400 \mu \mathrm{M} \mathrm{AlCl}_{3}\right.$ treatment $)$ 
at 19 day (Figure 1C). To further study the effects of aluminum stress on the growth of N. cadamba, the biomass of $N$. cadamba at 7 days treated with $400 \mu \mathrm{M} \mathrm{AlCl}_{3}$ was determined. In contrast to control plants, the aboveground dry weight and the belowground dry weight of $N$. cadamba seedlings in $400 \mu \mathrm{M} \mathrm{AlCl}_{3}$ decreased (Figure 1D,E), but this decrease was not statistically significant. This further indicated that $\mathrm{AlCl}_{3}$ could inhibit the root growth of N. cadamba under acidic conditions. Given that the effects of aluminum stress on growth of $N$. cadamba were mainly manifested by inhibition of root growth at early stage and increased severity with $\mathrm{Al}$ treatment, we further highlighted the changes in physiological and molecular mechanisms of $N$. cadamba treated with $400 \mu \mathrm{M} \mathrm{AlCl}_{3}$ for 0 days, 1 day, 3 days, and 7 days.
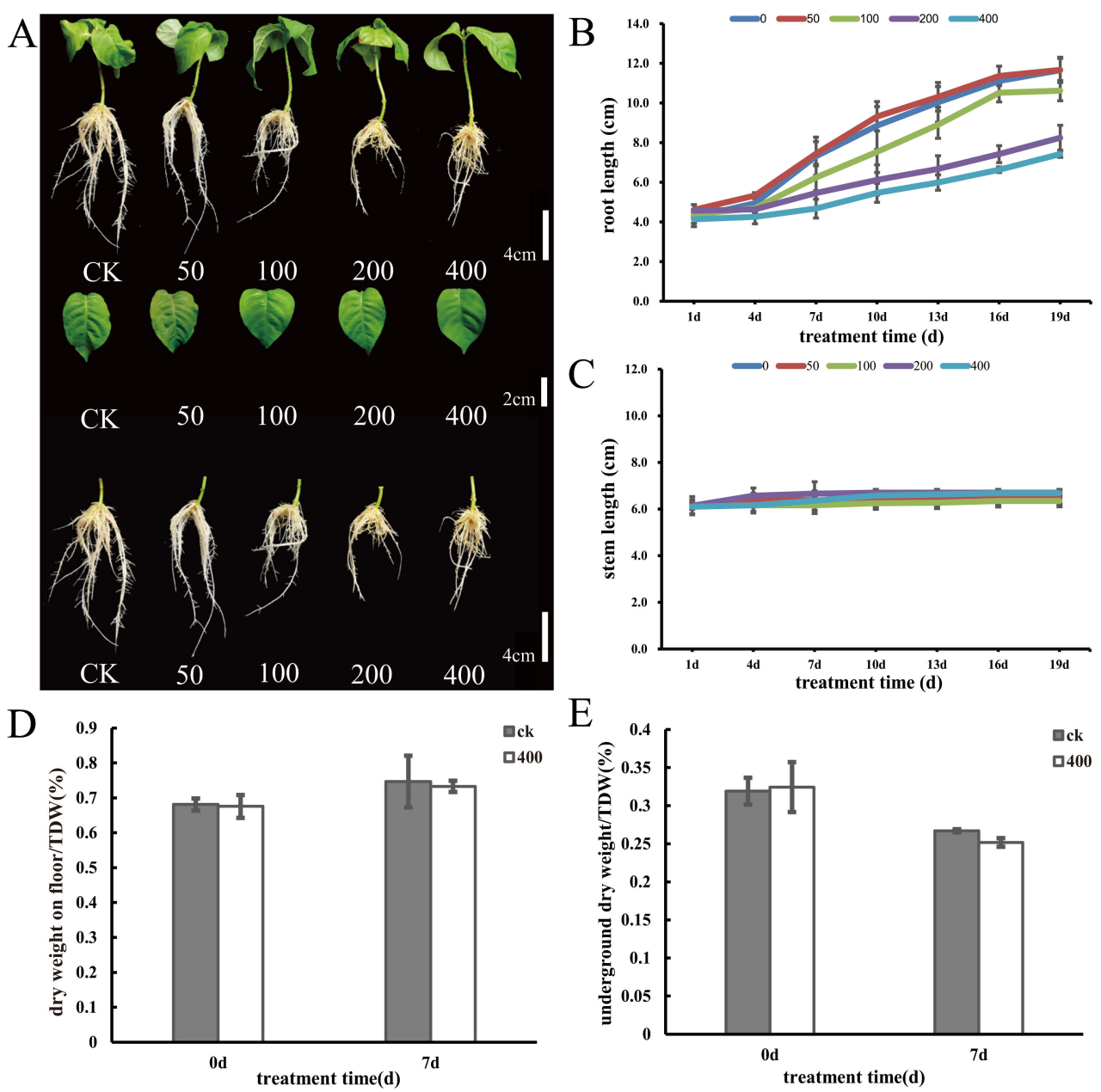

Figure 1. Effects of different concentrations of $\mathrm{AlCl}_{3}$ stress. (A) The comparison of plant, leaf, and root traits of $0 \mu \mathrm{M}(\mathrm{CK}), 50 \mu \mathrm{M}, 100 \mu \mathrm{M}, 200 \mu \mathrm{M}$, and $400 \mu \mathrm{M} \mathrm{AlCl}_{3}$ treatment for 24days. (B) Changing trend of root length under different concentrations of $\mathrm{AlCl}_{3}$ stress. (C) Changing trend of plant height under different concentrations of $\mathrm{AlCl}_{3}$ stress. (D) Changes of aboveground biomass under $\mathrm{AlCl}_{3}$ treatment for 0 days and 7 days. (E) Changes of belowground biomass under $\mathrm{AlCl}_{3}$ treatment for 0 days and 7 days. Results are mean \pm SD of three biological replicates. ck-control. $0-0 \mu \mathrm{M} / \mathrm{L}, 50-50 \mu \mathrm{M} / \mathrm{L}$, 100-100 $\mu \mathrm{M} / \mathrm{L}, 200-200 \mu \mathrm{M} / \mathrm{L}, 400-400 \mu \mathrm{M} / \mathrm{L}$.

\subsection{Inhibitory Effects of Aluminum Stress on N. cadamba Stem and Root Growth}

To explore the effects of aluminum stress on $N$. cadamba growth, the cross section of the third node of the stem and $1 \mathrm{~cm}$ root tip of plants were examined. The secondary xylem of third node treated with $400 \mu \mathrm{M} \mathrm{AlCl}_{3}$ for 1 day, 3 days, and 7 days (Figure 2B,D,F) was thicker than that of the control plantlets (Figure 2A,C,E). At the same time, there was no obvious change in the secondary xylem of control roots between 0 days and 7 th day (Figure 2G,H); however, the secondary xylem of the root tip was 
thickened on 7 th day after $400 \mu \mathrm{M} \mathrm{AlCl} l_{3}$ treatment (Figure 2I). This suggested that aluminum stress could increase the secondary xylem thickening of stem and root.
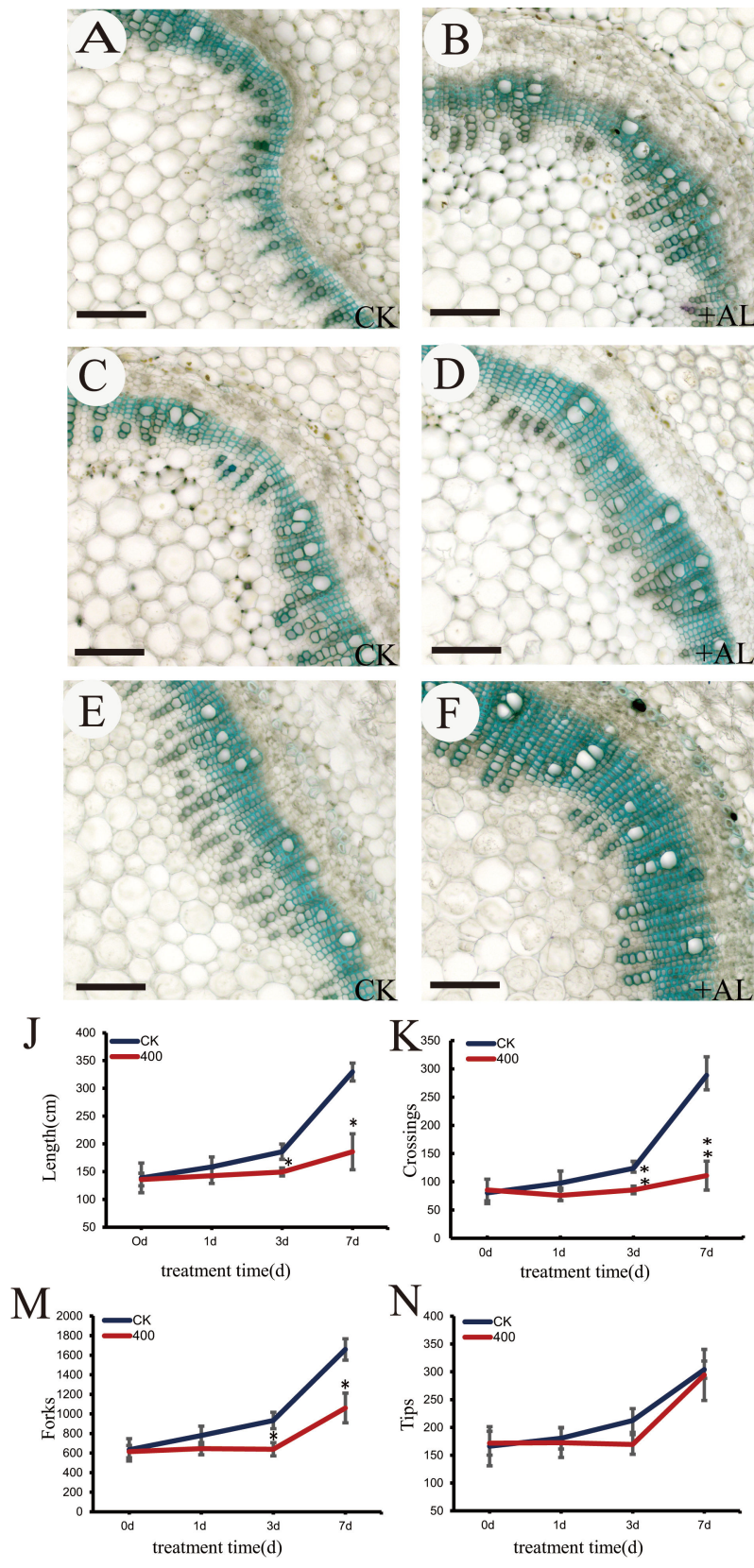
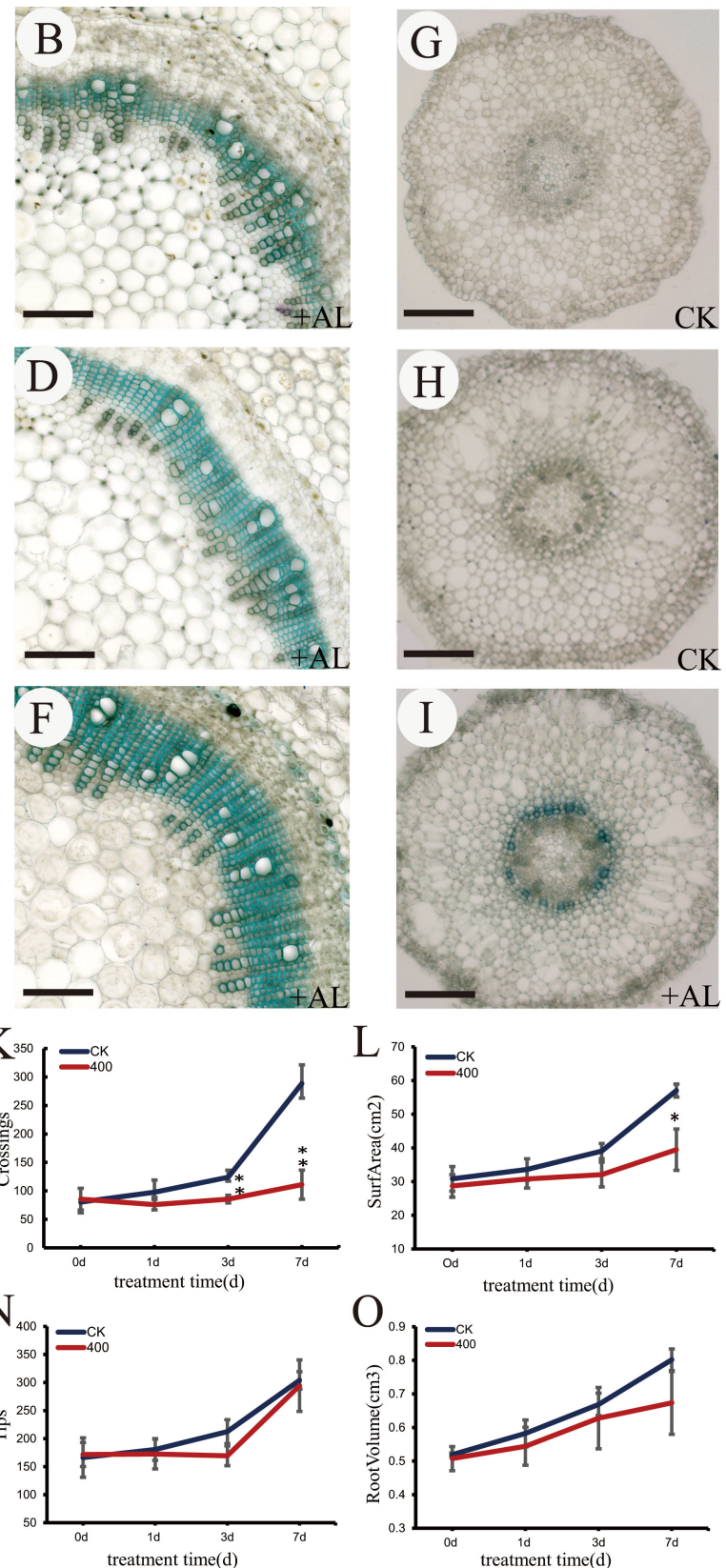

Figure 2. Aluminum stress inhibits the growth of stems and roots. (A,B) Stem section of control group and treatment group at 1 day. (C,D) Stem section of control group and treatment group at 3 days. (E,F) Stem section of control group and treatment group at 7 days. (G) Root tip section of control group at 1 day. (H) Root tip section of control group at 7 days. (I) Root tip section of treatment group at 7 days. The scale bar is $200 \mu \mathrm{m}$. (J) Total root length. (K) Cross number. (L) Surface area. (M) Branch root number. (N) Root tip number. $(\mathbf{O})$ Total root volume. The error line represents the average \pm SD of the three organisms. The * above the column chart indicated that the growth change between the two samples was significant (Students' $t$-test, ${ }^{*} p<0.05$, ${ }^{* *} p<0.01$ ). 

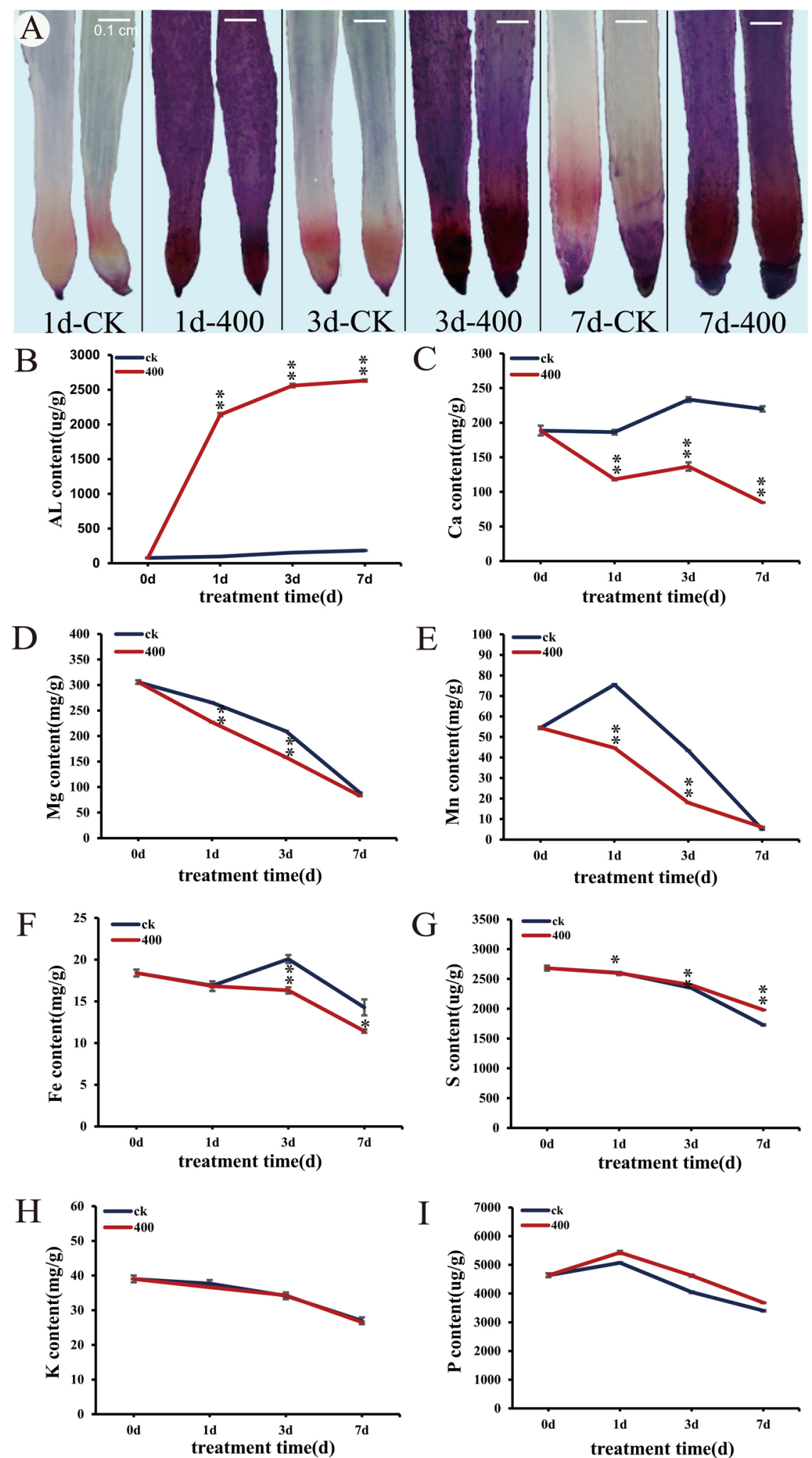

Figure 3. Absorption and distribution of aluminum by root tip. (A) Distribution of aluminum in root tip in different periods; the length of the root tip is $1 \mathrm{~cm}$. Eriochrome cyanine $\mathrm{R}$ staining does not show red and brown as the control group, but shows red and blue as the treatment group. (B-I) Changes of element concentration in root tip. The error line represents the average \pm SD of the three organisms (Students' $t$-test, ${ }^{*} p<0.05,{ }^{* *} p<0.01$ ). 
To further explore the inhibitory effects of aluminum stress on root growth, the whole root system of $N$. cadamba was scanned and analyzed after treatment with $400 \mu \mathrm{M} \mathrm{AlCl}{ }_{3}$ for 0 days, 1 day, 3 days, and 7 days, respectively. As shown, application of $400 \mu \mathrm{M} \mathrm{AlCl}_{3}$ significantly inhibited total root length (Figure 2J), branch root number (Figure 2M), root cross number (Figure 2K), and root surface area (Figure 2L), but not root tip number (Figure $2 \mathrm{~N}$ ) and total root volume (Figure 2O) after 7 days treatment. These results indicate that high aluminum stress could not only inhibit the root elongation, but also affects root morphology.

\subsection{Absorption and Distribution of Aluminum in Root Tip}

Considering that aluminum stress inhibited the growth and development of N. cadamba roots, we explore the distribution of $\mathrm{Al}^{3+}$ in N. cadamba roots. We thus used staining and chemical methods to locate the distribution and concentration of aluminum and other elements. Compared with the control samples, the aluminum-treated $1 \mathrm{~cm}$ root tip was deep-red and brown, with more pronounced staining in the root cap region (Figure 3A). We thus speculated that the N. cadamba, after quickly absorbing $\mathrm{Al}^{3+}$, preferentially accumulates it in the root tip, which later diffuses to the whole root and then affects the root growth and is transported to stem and leaf.

High $\mathrm{Al}^{3+}$ ion concentration causes an ionic imbalance in the root system, thus resulting in altered concentration of a large number of other elements in root. Accordingly, we evaluated the quantity changes of aluminum $(\mathrm{Al})$, calcium $(\mathrm{Ca})$, magnesium $(\mathrm{Mg})$, manganese $(\mathrm{Mn})$, iron $(\mathrm{Fe})$, potassium $(\mathrm{K})$, phosphorus $(\mathrm{P})$, and sulfur $(\mathrm{S})$ in the root tip of $N$. cadamba after aluminum stress. The results showed that in control samples, the aluminum concentration in root tip reached to $180 \mu \mathrm{g} / \mathrm{g}$ at 7 days, while in the Al-treated plant there was a sharp increase in $\mathrm{Al}$ concentration at 1 day from 0 to $2140 \mu \mathrm{g} / \mathrm{g}$ and reached to $2631 \mu \mathrm{g} / \mathrm{g}$ at $3 \mathrm{~d}$. However, the accumulation rate slowed down and became almost constant with time extension (Figure 3B). In the control group, the Ca concentration increased to $220 \mathrm{mg} / \mathrm{g}$ from 0 days to 7 days (Figure 3C), while the Ca concentration in the treatment group decreased to $118 \mathrm{mg} / \mathrm{g}$, $137 \mathrm{mg} / \mathrm{g}$, and $85 \mathrm{mg} / \mathrm{g}$ on the 1st, 3rd, and 7th day, respectively. Our results showed that $400 \mu \mathrm{M}$ $\mathrm{AlCl}_{3}$ treatment significantly increased the $\mathrm{Al}$ concentration and decreased the Ca concentration in N. cadamba on 1 day, 3 days, and 7 days.

Further analysis of other elements showed that aluminum stress affected the concentration of $\mathrm{Mg}$, $\mathrm{Mn}, \mathrm{Fe}$, and P elements in the root tip of $N$. cadamba. Compared with the control, the concentrations of $\mathrm{Mg}$ (Figure 3D) and $\mathrm{Mn}$ (Figure 3E) in the root tip of N. cadamba treated with $400 \mu \mathrm{M} \mathrm{AlCl} 3$ for 1 day and 3 days were significantly decreased, but at the 7 days, they have same concentration. The Fe concentration (Figure 3F) was significantly decreased under aluminum stress at 3 days, and reached to $11 \mathrm{mg} / \mathrm{g}$ at 7 days. Likewise, the concentration of $S$ element (Figure 3G) was significantly increased under aluminum stress for 1 day $(p<0.05), 3$ days, and 7 days $(p<0.01)$, but not $\mathrm{K}$ (Figure $3 \mathrm{H}$ ) and P (Figure 3I).

\subsection{Effects of $A l^{3+}$ Stress on Antioxidant Enzymes}

In an acidic environment, aluminum stress can cause an accumulation of MDA, which leads to membrane lipid peroxidation, and increases SOD, POD, and CAT to maintain the stability of the cell membrane by scavenging ROS in an adverse environment [20]. Here, the MDA content and activities of SOD, CAT, and POD in leaves and root tips were determined after aluminum stress. The MDA content did not show obvious differences in the leaves (Figure 4A), but had an obvious decrease in root at 3 days and 7 days after treated with $\mathrm{Al}$ (Figure 4B), indicating that membrane peroxidation could occur in root after 3 days. Different from leaves (Figure 4C,E,G), the activities of SOD, CAT, and POD in roots were also increased from 1 day to 7 days (Figure $4 \mathrm{D}, \mathrm{F}, \mathrm{H}$ ).

In addition, the chlorophyll content of $N$. cadamba after aluminum stress was quantified. The chlorophyll content decreased under aluminum stress from 1 day, 3 days, and 7 days, and the decrease in chlorophyll content under aluminum stress at 1 day was greater than 3 days and 7 days (Figure 4I). Aluminum stress can therefore cause rapid degradation of chloroplasts. 

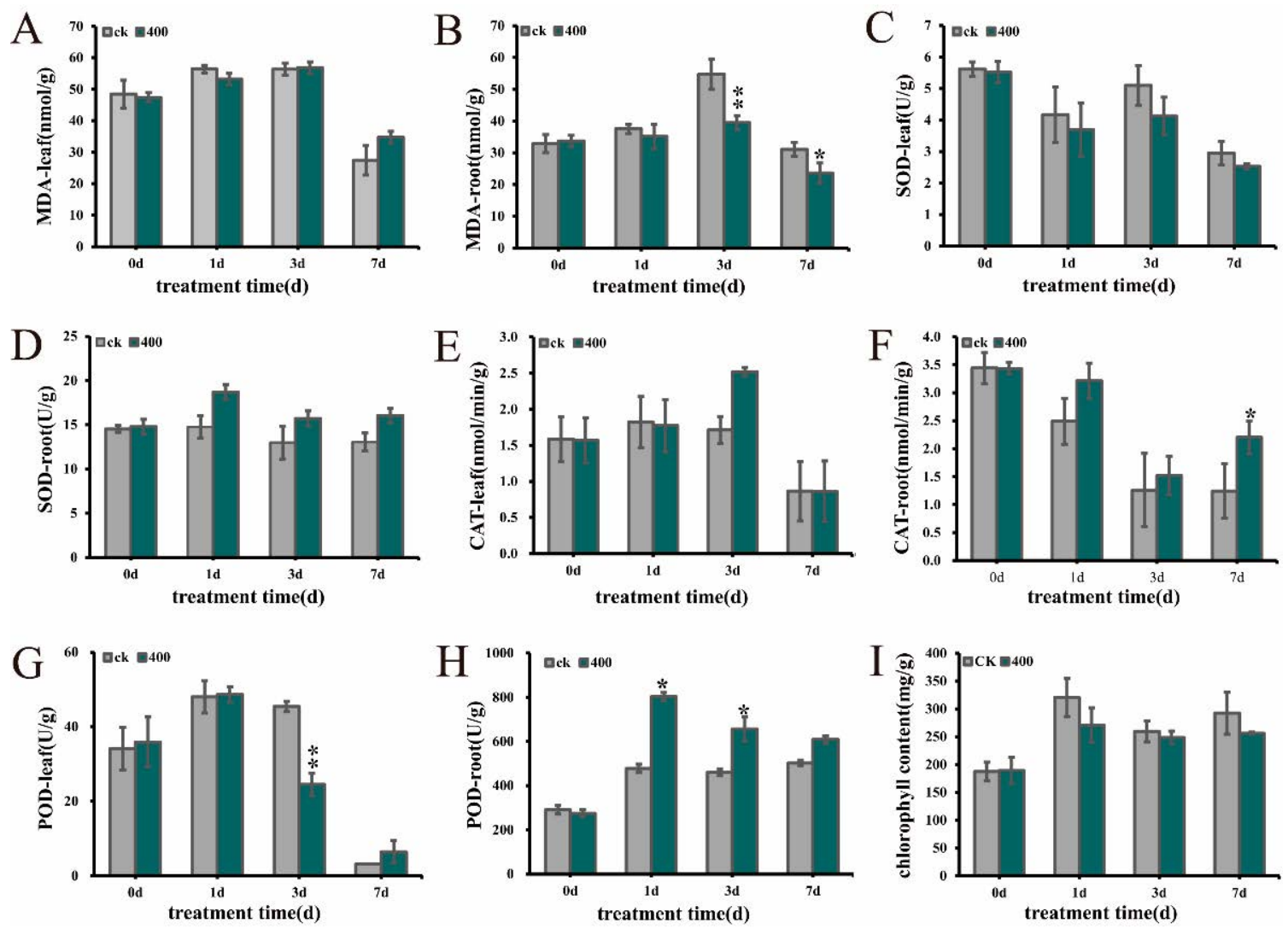

Figure 4. Effects of aluminum stress on ROS and chlorophyll. (A-H) Changes of ROS in leaves and root tips. (I) Chlorophyll content change. The error line represents the average $\pm \mathrm{SD}$ of the three organisms. The * above the column chart shows that the content of elements between the two samples was significant (Students' $t$-test, ${ }^{*} p<0.05,{ }^{* *} p<0.01$ ).

\subsection{DEGs Shown in Aluminum Stress of N. cadamba by Transcriptome Sequencing Analysis}

Aluminum stress mainly affected the growth and development of N. cadamba roots (Figure 1A); we thus studied the molecular mechanisms of $N$. cadamba roots in response to aluminum stress through RNA-seq. There was a total of 1,252,105,064 clean reads based on the quality evaluation as shown in Supplementary Table S1. The filtered sequences were analyzed for genome location, and the comparison between reads and the reference genome is shown in Supplementary Table S2. The reads alignment to the genome was more than $90 \%$, and the match sequence of $85.88-92.16 \%$ was uniquely aligned to the reference genome, which satisfies the follow-up analysis. The Pearson correlation coefficient (R2) was greater than 0.92 correlation inspection index to test the correlation of gene expression levels between samples. The test results are as shown in Supplementary Figure S1, which indicates that repeatability of the data under three biological replicates of are good enough.

To explore the mechanism of aluminum stress on $N$. cadamba at different times, genes from twenty-one libraries were assembled and six groups were compared (AL1_400 vs. AL1_CK, AL3_400 vs. AL3_CK, AL7_400 vs. AL7_CK, AL1_400 vs. AL0, AL3_400 vs. AL1_400, and AL7_400 vs. AL3_400). The volcanic map was established to determine the overall distribution of DEGs in response to aluminum stress at different time Figure S2, and, evaluated from the difference multiple and significant level, the result shows that a total 77,705 DEGs was selected from the six groups of comparison combinations, and the number of DEGs in the three horizontal comparison combinations of AL1_400 vs. AL1_CK, AL3_400 vs. AL3_CK, and AL7_400 vs. AL7_CK was much greater than that of the three vertical comparison combinations of AL1_400 vs. AL0, AL3_400 vs. AL1_400, and AL7_400 vs. AL3_400. 


\subsection{Verification of DEGs Through $q R T-P C R$}

The RNA-seq sequencing data showed lots of DEGs that were significantly upregulated or downregulated after aluminum stress. To verify these DEGs, 18 DEGs relative expression patterns in three comparative combinations, i.e., AL1_400 vs. AL1_CK, AL3_400 vs AL3_CK and AL7_400 vs. AL7_CK were randomly selected for qRT-PCR detection (Figure 5). The corresponding primer pairs were listed in Table S3. Of note, more than $94 \%$ of the gene expression patterns were consistent with RNA-seq sequencing results, so the results of RNA-seq sequencing data were reliable and repeatable. Next all DEGs were analyzed by principal component analysis (PCA). The obvious different abundance hierarchical clusters between the 0 days, 1 day, 3 days, and 7 days treatment groups and control group are shown in Figure 6A. This implies that aluminum treatment leads to the increase in total number of DEGs. Then, through the statistics of the difference of each gene in the root of N. cadamba under aluminum stress, there are 28,633 DEGs significantly expressed; the number of upregulated genes was significantly more than that of downregulated genes in the comparison between the treated group (R_400) and the control group (R_WT). However, the number of downregulated genes was significantly more than that of upregulated genes in the comparison combination between different time treatment groups (R_400) and 0 days control group (Figure 6B). Two Venn maps were constructed to analyze the common and specific DEGs in response to aluminum stress (Figure $6 \mathrm{C}, \mathrm{D}$ ). The results show that there were 1393 DEGs overlapping and stably expressed in the treatment groups and the control group; however, just 237 DEGs were expressed in the different time treatment groups and the control group.

\subsection{Functional Enrichment Analysis of DEGs}

Through gene annotation of sequence alignment with the model plant Arabidopsis thaliana, DGEs were shown in the following databases: GO (2405), NR (775), Swissprot (3058), KEGG (1193), and IPRSCAN (2405). In order to further analyze the function of DEGs during aluminum stress in N. cadamba root at different time intervals, we analyzed the DEGs by using the GO and KEGG databases. The enrichment GO terms (Figure S3) of DEGs to biological processes during aluminum stress for 1 day, 3 days, and 7 days include ion transport (GO:0006811), response to oxidative stress (GO:0006979), glucan metabolic process (GO:0006073, GO:0044042), and carbohydrate metabolic process (GO:0005975); the enriched GO term to cellular components include cytoplasm (GO:0044444, GO:0005737), cell wall (GO:0005618), and external assembly structure (GO:0030312); and the enriched GO term to molecular functions include ion transmembrane transporter activity (GO:0015075), inorganic molecular entity transmembrane transporter activity (GO:0015318), oxidoreductase activity, acting on paired donors, with incorporation or reduction of molecular oxygen (GO:0016705), and ion transmembrane transporter activity (GO:0015075).

The enriched KEGG analysis of all the DEGs of six differential combinations showed that a total of 416 metabolic pathways were involved in response of $N$. cadamba to aluminum stress at 1 day, 3 days, and 7 days. In this study, the related pathways of aluminum stress at different times ranked in the top 20 are shown in Figure 7. It was mainly enriched in phenylpropane biosynthesis and secondary metabolite biosynthesis pathway, followed by steroid biosynthesis, cysteine, and methionine metabolic pathway (FDR $<0.05$ ). The enriched results of GO and KEGG showed that $N$. cadamba would adjust its metabolism to respond to aluminum stress. On the other hand, through the trend cluster analysis of the DEGs in different combinations after aluminum stress at different times, it is suggested that the DEGs of the treatment group and the control group may have similar functions or participate in the same metabolic process or cellular pathway together (Figure S4). 

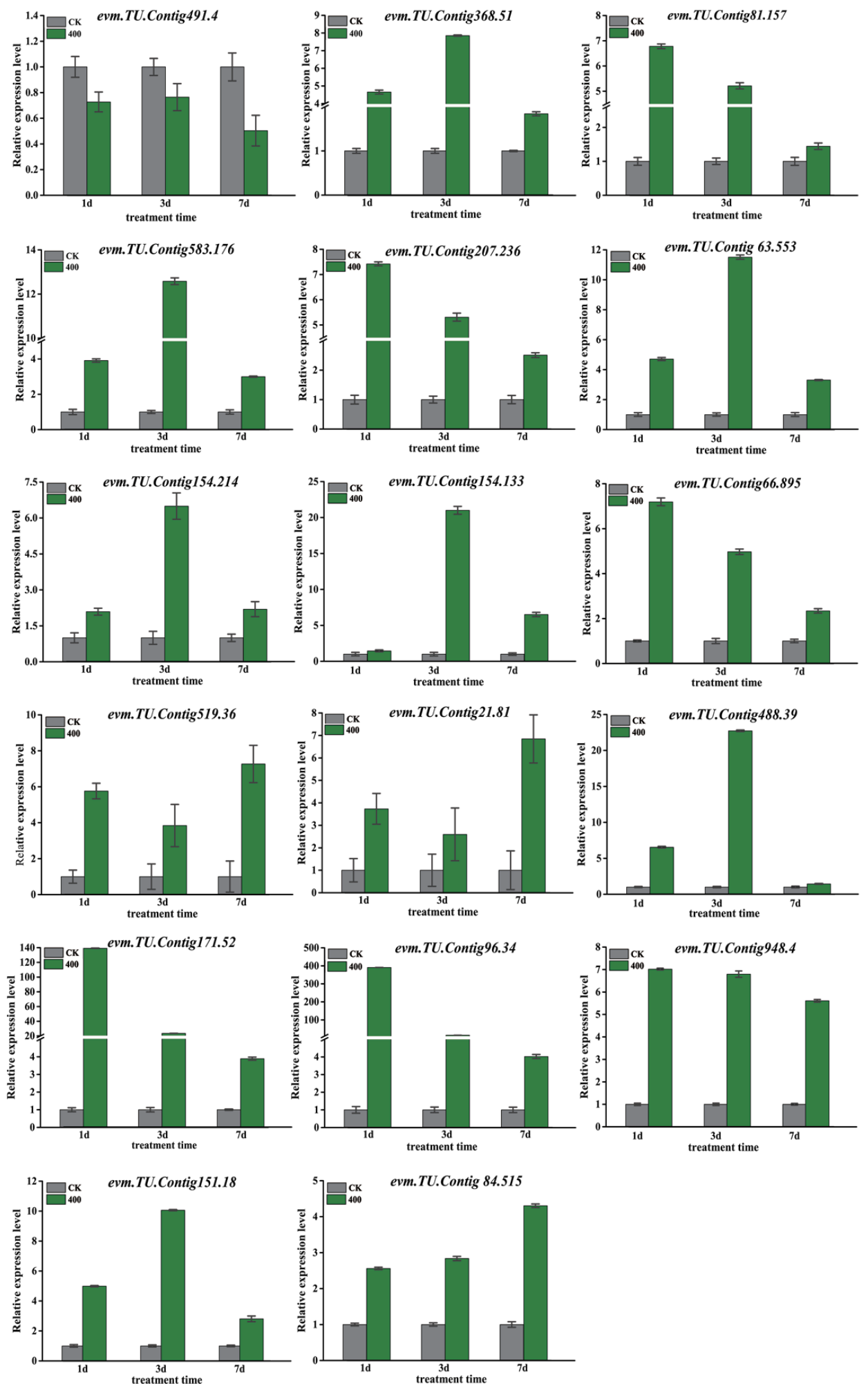

Figure 5. qRT-PCR verifies the relative expression levels of differential expression genes (DEGs) at different times under aluminum stress. Transport (evm.TU.Contig488.39, evm.TU.Contig519.36, evm.TU.Contig154.214, evm.TU.Contig154.133, evm.TU.Contig491.4, evm.TU.Contig63.553); transcription factor (evm.TU.Contig96.34, evm.TU.Contig948.4, evm.TU.Contig151.18, evm.TU.Contig84.515); protein (evm.TU.Contig368.51, evm.TU.Contig81.157, evm.TU.Contig 171.52, evm.TU.Contig583.176, evm.TU.Contig207.236, evm.TU.Contig66.895, evm.TU.Contig 21.81). 

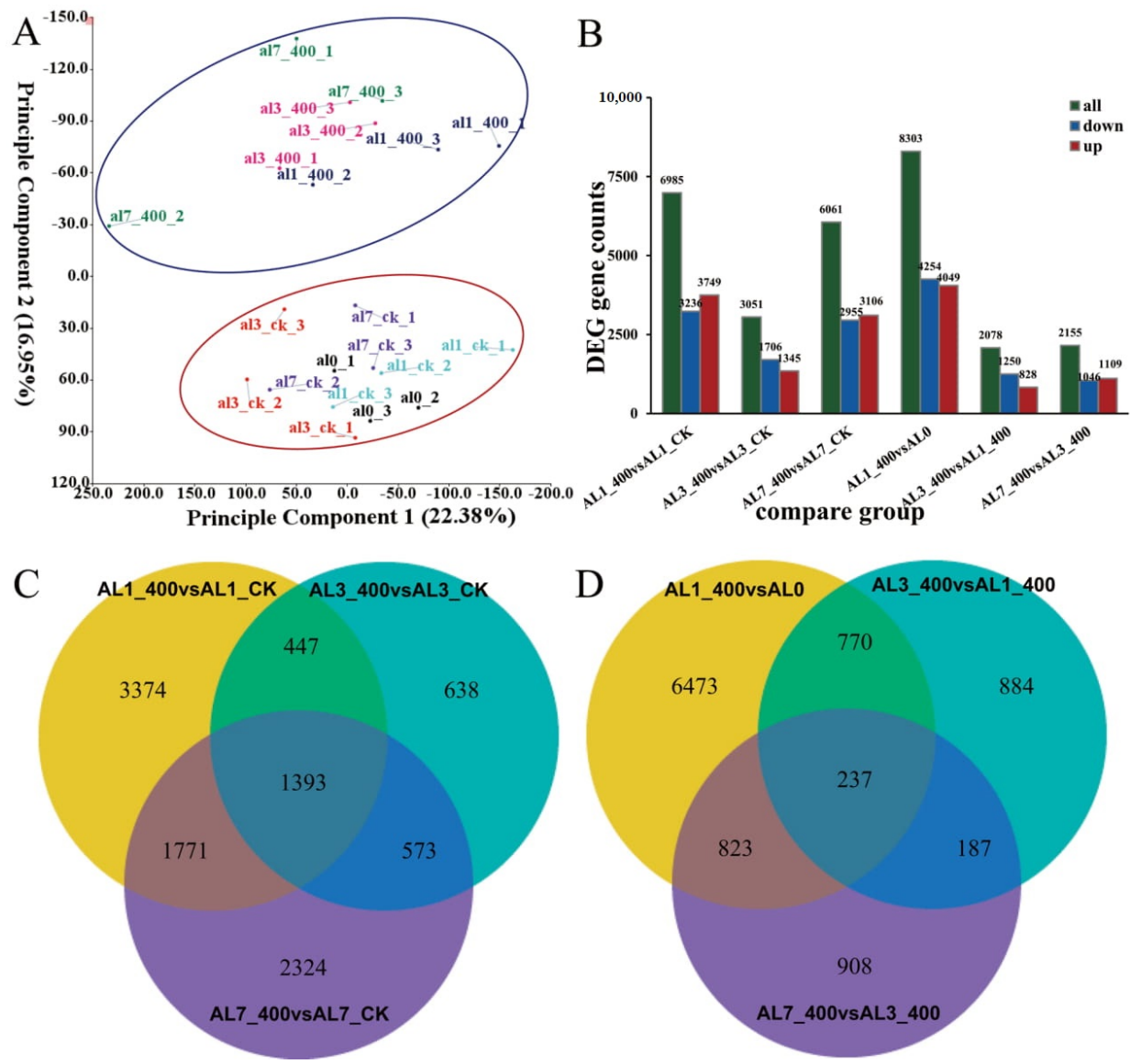

Figure 6. The DEGs of N.cadamba in response to aluminum stress. (A) Principal component analysis (PCA) of DEGs: diagram of treatment group and control group at 0 days, 1 day, 3 days, 7 days, the dots with the same color represent 3 biological replicates of the same treatment group, the blue area and the red area are the treatment group and control group gene cluster, respectively. (B) The green bar represents all DEGs, downregulated DEGs are in blue, and upregulated DEGs are in red, FDR $<0.05$. (C,D) The overlapping area represents the DEGs with a common regulation mode between different treatments.

On the other hand, we also compared the three combinations of AL1_400 vs. AL0, AL3_400 vs. AL1_400, and AL7_400 vs. AL3_400 longitudinally to analyze the gene function clustering of N. cadamba after aluminum stress. We found that the key GO terms (Figure 8) enriched in the biological process include transmembrane transport (GO:0055085), transport (GO:0006810), response to stress (GO:0006950), etc. The molecular functions were mainly enriched in the cofactor binding, transition metal ion binding (GO:0048037, GO:0046914), and transcriptional regulation (GO:0016772, GO:0140110, GO:0003700). The cellular components were mainly enriched in membrane function (GO:0043231, GO:0044425, GO:0031224, GO:0016021, GO:0043227). The results revealed that there were significant differences in transcriptional regulation, metabolic processes, transport processes, and membrane functions induced by aluminum stress in different periods, which further indicated that the effects of aluminum stress on $N$. cadamba was significantly differed over time.

Comparative analysis with Arabidopsis thaliana genes showed that the relative expression of DEGs in the three combinations of AL1_400 vs. AL0, AL3_400 vs. AL1_400, and AL7_400 vs. AL3_400 (Figure S5), the expression of DEGs in different periods of aluminum stress was mainly downregulated by unknown functional gene evm.TU.Contig 491.32 acting on the membrane, unknown functional gene evm.TU.Contig477.376, and new gene novel.619 responding to stress. The main upregulated genes in different periods were transcription factor NAC090 (evm.TU.Contig488.87), kinase evm.TU.Contig108.3, 
and enzyme FRO2 (evm.TU.Contig477.127), which can participate in heavy metal transport gene HIPP26 (evm.TU.Contig262.36), and some unknown functional genes were also upregulated.
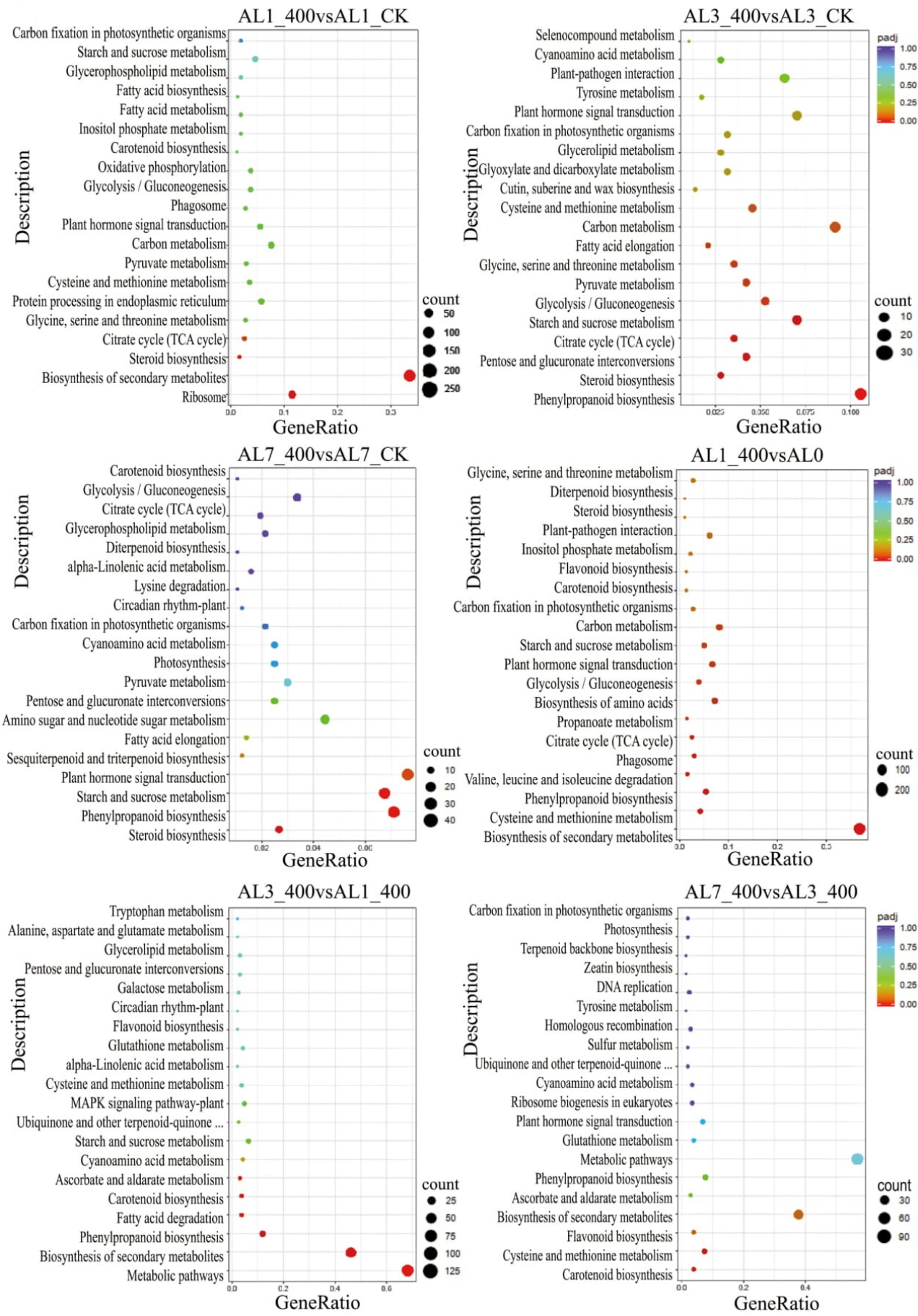

Figure 7. KEGG (Kyoto Encyclopedia of Genes and Genomes) enrichment of six comparative combinations of aluminum stress in different periods. The ordinate indicates the name of the pathway, the abscissa indicates the rich factor, the size of the dot indicates the number of differentially expressed genes in the pathway, and the color of the dot corresponds to different $q$ value ranges. 


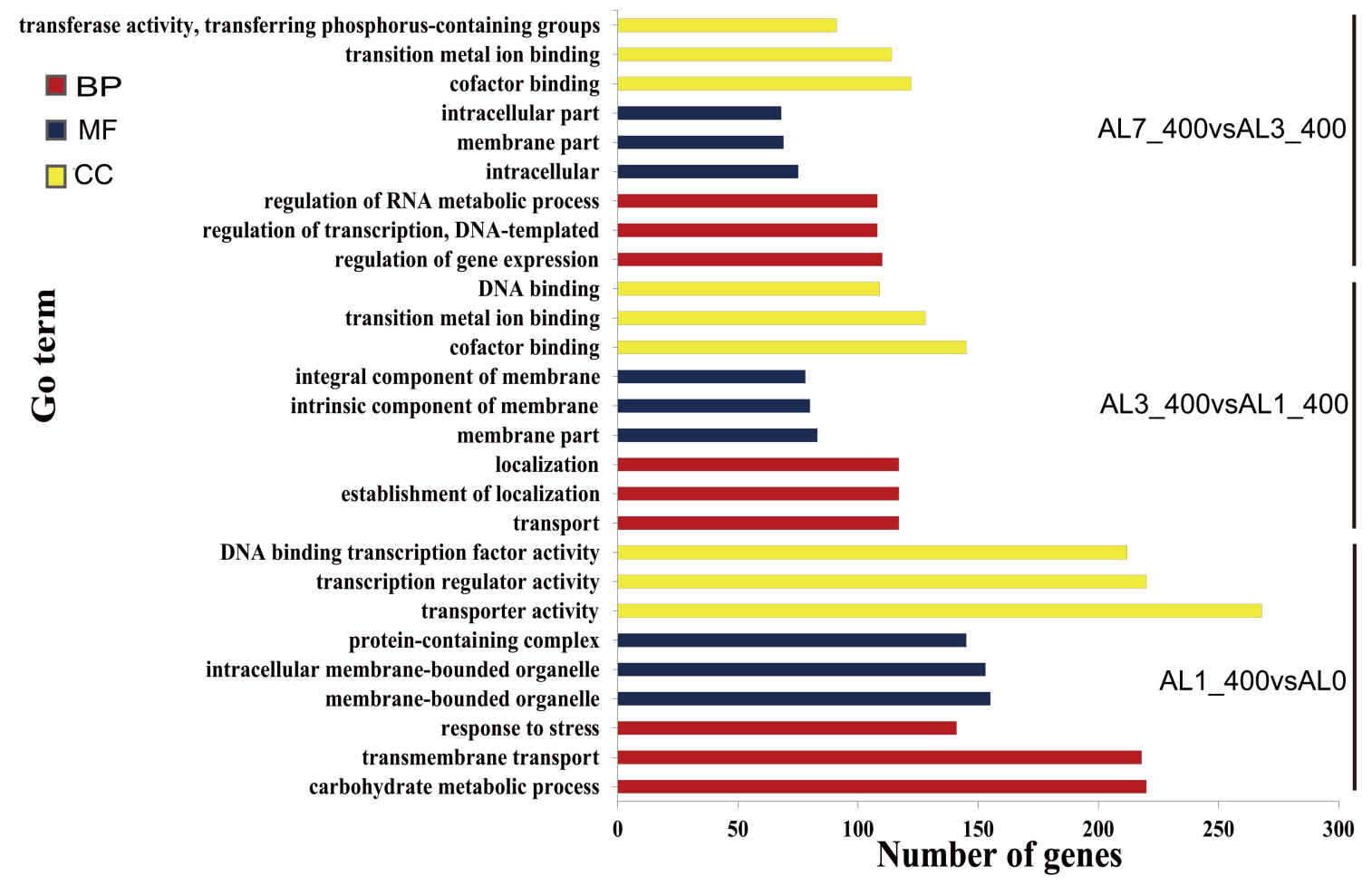

Figure 8. Differential gene GO enrichment among different combinations of aluminum stress comparison. The abscissa is the GO term, the enrichment is the number of differential genes in the term, and $27 \mathrm{GO}$ terms with the most significant enrichment in different periods are selected to show in the map. The red bar column represents the DEGs which enriched on biological process; the blue bar column represents the DEGs which enriched on molecular function; the yellow bar column represents DEGs which enriched on cellular component.

\subsection{Effects of Aluminum Stress on Cell Wall}

The cell wall is the most important site of aluminum accumulation in $\mathrm{Al}$ stress. Al stress results in an increase in the lignin content. According to the RNA-seq data, the expression of 16 DEGs genes involved in the synthesis of phenylalanine lignin monomer induced by aluminum stress was screened (Figure 9A). Several key enzymes involved in the synthesis of lignin monomer were upregulated at different stages after aluminum stress. For instance, the expression of genes similar to Arabidopsis thaliana PALA (evm.TU.Contig766.86), CCR1 (evm.TU.Contig45.284),CAD (evm.TU.Contig 462.293), and 4CL1 (evm.TU.Contig600.113) were significantly upregulated at 1 day, 3 days, and 7 days of aluminum stress. The proportion of upregulated genes involved in phenylalanine biosynthesis was higher in different periods, indicating that in N. cadamba root cell wall thickness and decreased cell wall malleability were regulated by altered lignin synthesis during aluminum stress.

In this study, it was found that aluminum stress not only decreased the extensibility of the cell wall of root tip, but also decreased the remodeling of the cell wall. The synergistic effect of these two aspects led to inhibition of root growth. By calculating the FPKM values of different combinations under different treatment times (Figure 9B-D), we found that the expression of XTH family genes (evm.TU.Contig63.448, evm.TU.Contig180.195, evm.TU.Contig553.99, evm.TU.Contig28.439, evm.TU.Contig180.196, and evm.TU.Contig35.15) were significantly downregulated; moreover, the demethylation and esterification of cell wall pectin, regulated by PME gene family (evm.TU.Contig284.2, evm.TU.Contig612.63, and evm.TU.Contig600.380), was decreased significantly at 1 day, 3 days, and 7 days during aluminum stress. 
A phenylalanine

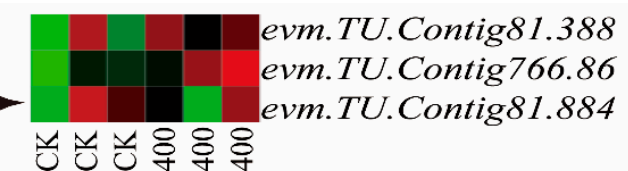

evm.TU.Contig81.388
evm.TU.Contig766.86

evm.TU.Contig81.884

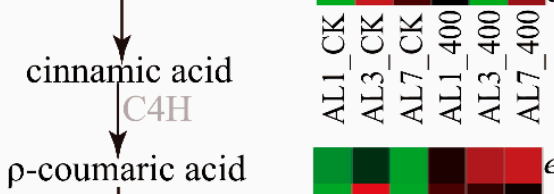

evm.TU.Contig600.113

光记记 \& \& 8

evm.TU.Contig21.361

evm.TU.Contig555.80

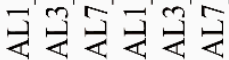

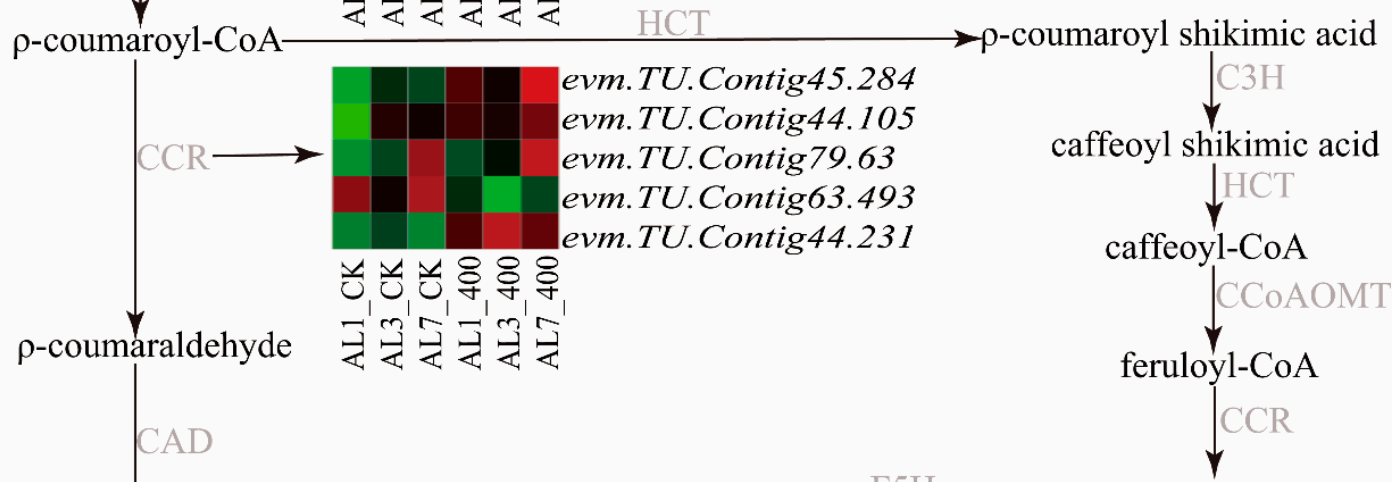

$\underset{\rho \text {-coumaryl alcohol }}{\downarrow}$

5-hydroxy-coniferaldehyde

coniferaldehyde

p-colyal alcohol

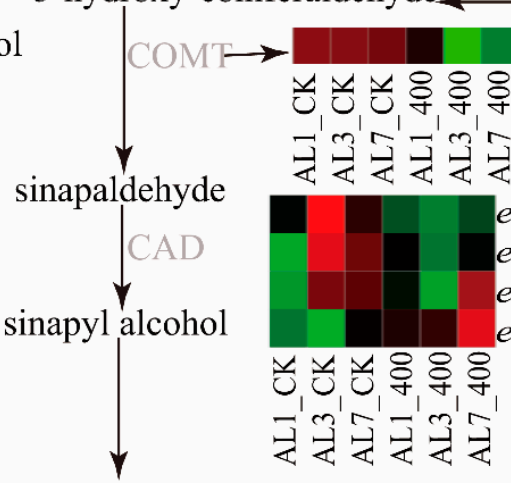

evm.TU.Contig985.19

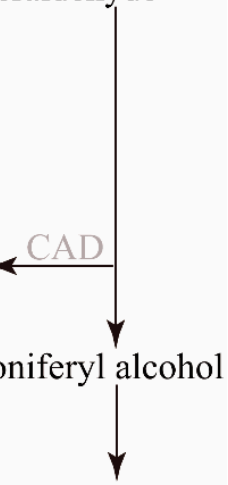

$\mathrm{H}$ lignin

S lignin

$\mathrm{G}$ lignin
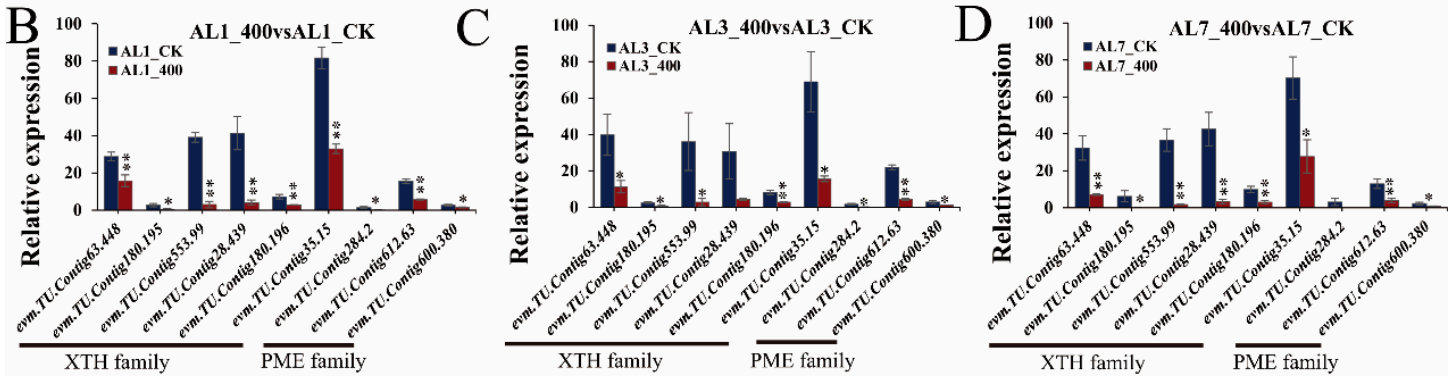

Figure 9. Expression of cell wall-related genes induced by aluminum stress. (A) Enrichment of DEGs in the phenylalanine pathway. (B-D) XTH/PME family DEGs relative expression. FDR $<0.05$, $\mid \log _{2}$ (FoldChange) $\mid>1$. The * above the column chart showed that the electrical conductivity changed significantly between the two samples $\left({ }^{*} p<0.05,{ }^{* *} p<0.01\right)$.

\subsection{Transport-Related Genes Respond to Aluminum Stress}

As shown in Figure 10A, aluminum stress induced the expression of transporters and protein kinases in N. cadamba. Importantly, among DEGs, transporter-encoding genes such as ABC, ALMT, MATE, and ZAT families are enriched. For example, the evm.TU.Contig46.7, 
evm.TU.Contig7.260, and evm.TU.Contig21.352 genes encoding the bacterial ABC transporter family were significantly upregulated. The ALMT family genes (evm.TU.Contig154.214, evm.TU.Contig154.133, evm.TU.Contig488.39_evm.TU.Contig488.40, and evm.TU.Contig488.38), MATE family genes (evm.TU.Contig490.37, evm.TU.Contig81.157, and evm.TU.Contig66.895), and evm.TU.Contig63.553 similar to Arabidopsis thaliana AtALS1 genes involved in organic acid regulation were significantly upregulated at different stages of aluminum stress, suggesting that $N$. cadamba can tolerate aluminum stress on roots by increased secretion of organic acids. In addition, the expressions of evm.TU.Contig447.151, evm.TU.Contig765.14, evm.TU.Contig14.131, and evm.TU.Contig421.426 genes, homologs of the of Arabidopsis thaliana sugar transporter ERD family, were downregulated during aluminum stress, indicating that $N$. cadamba could modulate its glucose metabolism and root nutrient absorption in response to aluminum stress. Additionally, the uptake and transport of other elements were affected by aluminum uptake. Together, aluminum stress altered the expression of different transporters. For example, the expression of intracellular calcium transduction signal gene CCR1 (evm.TU.Contig63.493) and magnesium transport protein regulatory gene evm.TU.Contig16.298 was significantly downregulated. These results are in accordance with the decreased concentration of calcium and magnesium (Figure $3 \mathrm{C}, \mathrm{D}$ ). Although the potassium concentration has not changed in treatment, the expression of POT genes (evm.TU.Contig41.8, evm.TU.Contig341.538) regulating potassium transporter family was upregulated during aluminum stress.
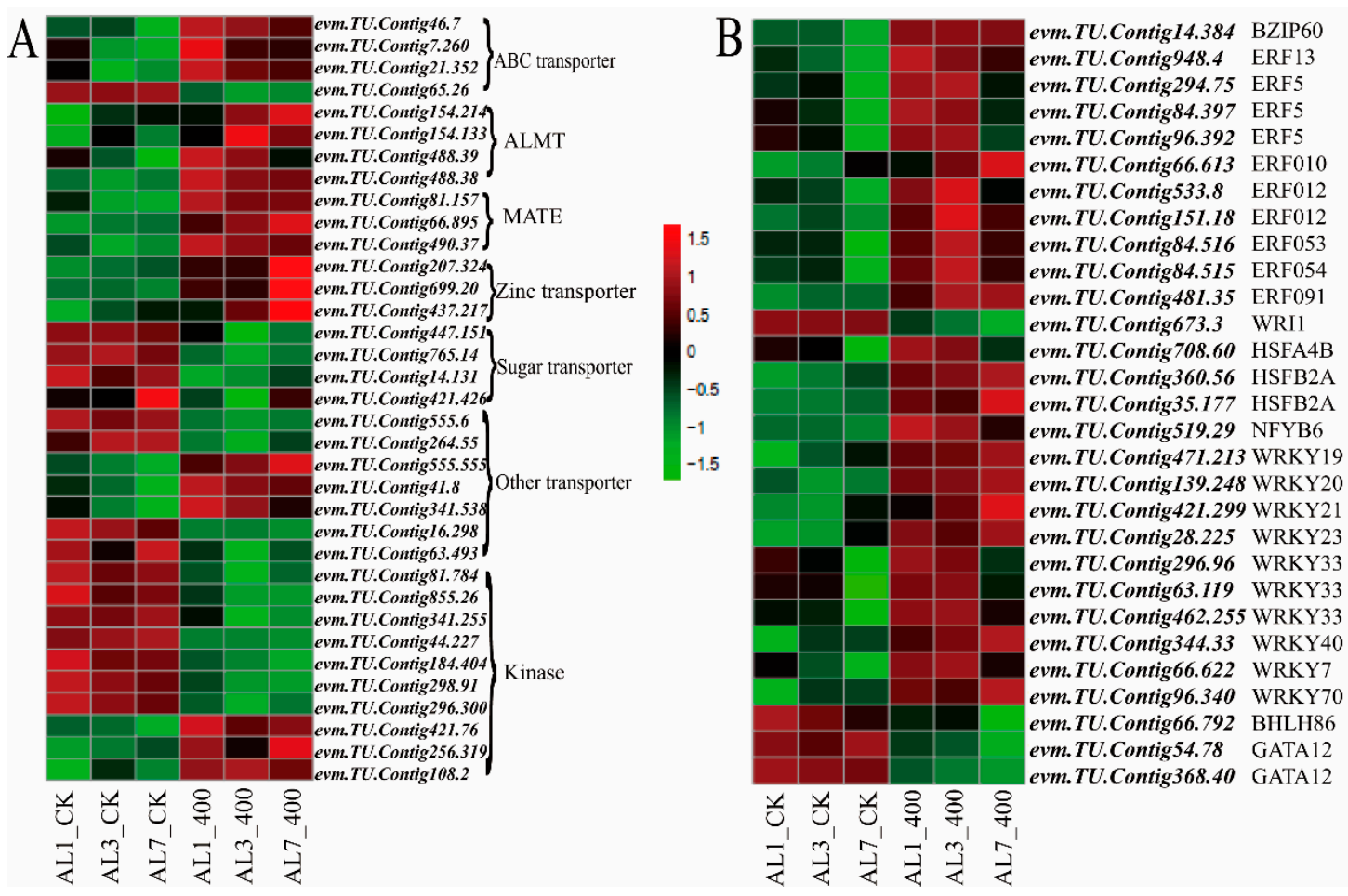

Figure 10. Expression of related transporters and transcription factors induced by aluminum stress. The threshold of FDR $<0.05, \mid \log 2$ (FoldChange) $\mid>1$ was used to screen the changes of differential gene expression between the treated group and the control group after aluminum stress at different times. (A) Heat map of aluminum transport-related gene and related protein kinase expression induced by aluminum stress. (B) Heat map of transcription factor-related gene expression induced by aluminum stress.

The aluminum stress-induced transporters may conduct the signals through the corresponding protein kinases. The data analysis showed that aluminum stress could significantly affect expressions of some transport-related proteins and protein kinase regulatory genes (Supplementary Table S4) the higher expression of these genes may also raise aluminum absorption and transport. In addition, 
the expression of auxin steady-state protein kinase TMK1 (evm.TU.Contig298.91), auxin signal transduction kinase PKS1 (evm.TU.Contig184.404), and polar developmental receptor-like kinase PXL family genes (evm.TU.Contig81.784, evm.TU.Contig855.26, evm.TU.Contig341.255) were significantly downregulated at different stages of aluminum stress. However, the expression of evm.TU.Contig256.319 and evm.TU.Contig108.2 that may be involved in the abscission process and oxidative burst transduction kinase OXI1 (evm.TU.Contig421.76) was significantly upregulated.

\subsection{Response of Transcription Factors to Aluminum Stress}

Transcription factors play important roles on the stress tolerances in higher plants. Our RNA-seq showed that some ERF and WRKY transcription factors were significantly upregulated in the root tip under aluminum stress (Figure 10B). The expressions of these genes were similar to Arabidopsis thaliana WRKY23 (evm.TU.Contig28.225), WRKY33 (evm.TU.Contig462.255), WRKY7 (evm.TU.Contig66.622), WRKY70 (evm.TU.Contig96.340), and so on were significantly upregulated, and the expression of ethylene-responsive transcription factor ERF family genes were upregulated during aluminum stress. The expression of BZIP60 (evm.TU.Contig14.384), a zinc finger transcriptional factor, was significantly upregulated under aluminum stress, indicating that WRKY, ERF, and ZIP family genes were involved in downstream genes network in response to aluminum stress. HSFB2A (evm.TU.Contig360.56, evm.TU.Contig35.177) and HSFA4B (evm.TU.Contig708.60) genes were significantly upregulated (Figure 10B), indicating that N. cadamba may induce heat shock HSF family genes also participating aluminum stress response pathway.
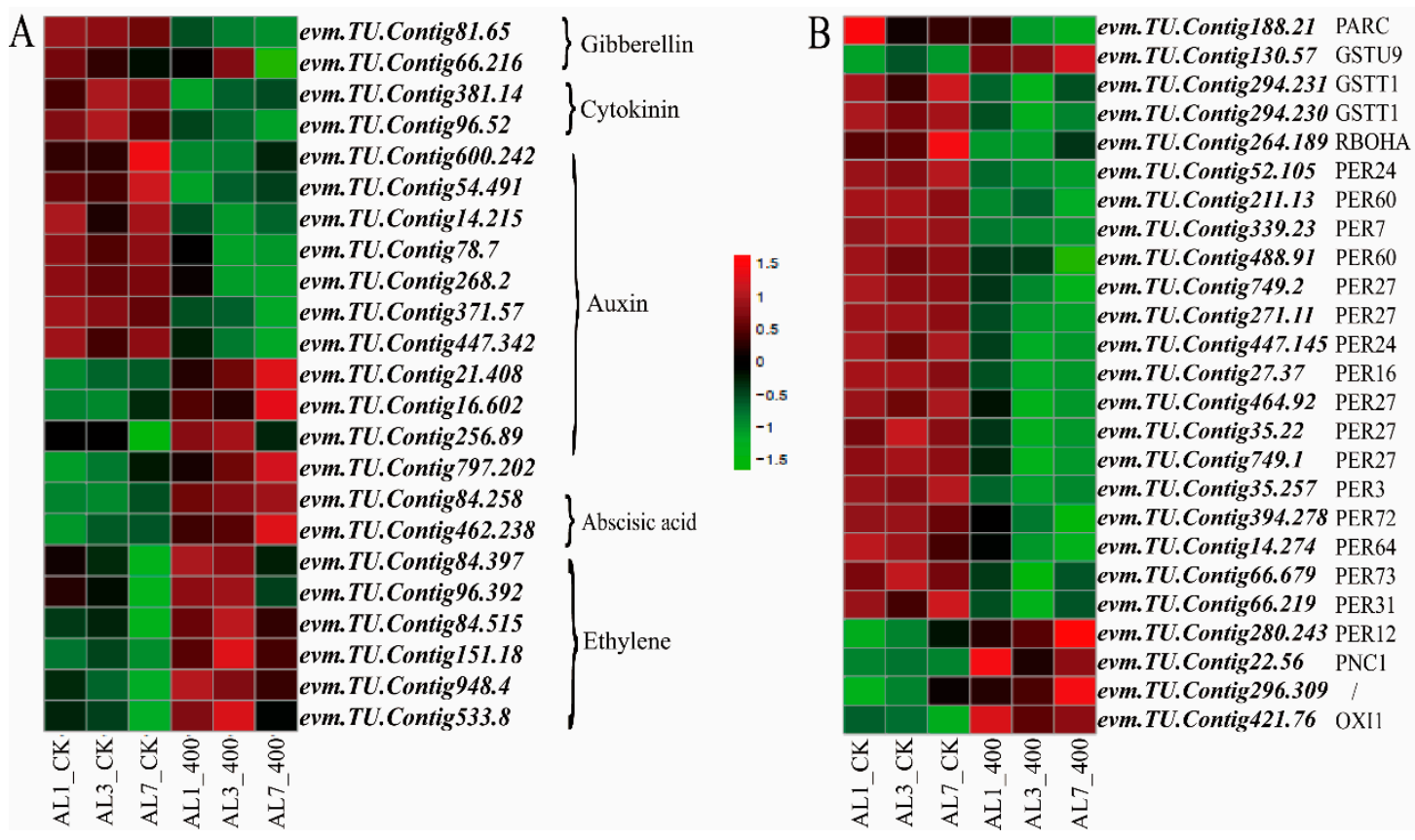

Figure 11. Aluminum stress induces the expression of ROS and hormone-related genes. The threshold of FDR $<0.05, \mid \log 2$ (FoldChange) $\mid>1$ was used to screen DEGs between the treated group and the control group after aluminum stress at different times. (A) Heat map of hormone-related gene expression. (B) Heat map of ROS-related gene expression.

\subsection{Hormone-Related Genes Respond to Aluminum Stress}

Plant hormones are key to plant growth and adaptation to various stress conditions; the expression level of hormone-related genes induced by aluminum stress in the root tip are shown in Figure 11A. Aluminum stress significantly downregulated the expression of auxin response factor (ARF) evm.TU.Contig21.408 in auxin response and downregulated the expression of downstream genes IAA7 (evm.TU.Contig447.342, evm.TU.Contig78.7) and similar genes LAX3 (evm.TU.Contig268.2) and 
PIN3 (evm.TU.Contig371.57) in Arabidopsis thaliana after 1 day, 3 days, and 7 days aluminum stress. The expression of SAUR36 (evm.TU.Contig256.89, evm.TU.Contig797.202) was upregulated, the downregulation of auxin-regulated genes may regulate the down-regulation of auxin receptor protein gene ABP20 (evm.TU.Contig600.242). This suggests that regulating the expression of auxin-related genes might be a key factor in inhibition of root tip growth by aluminum stress.

Ethylene is a key hormone that inhibits plant growth and development. In the present study, aluminum stress significantly upregulated expression of ERF family genes (evm.TU.Contig948.4, evm.TU.Contig151.18, evm.TU.Contig533.8, evm.TU.Contig84.515, and evm.TU.Contig84.397, evm.TU.Contig96.392). Meanwhile, expression of abscisic acid receptor gene PYL4 (evm.TU.Contig84.258 and evm.TU.Contig462.238) was significantly upregulated, while gibberellin-regulated genes GASA9 (evm.TU.Contig81.65) and GASA14 (evm.TU.Contig66.216), and cytokinin-regulated genes LOG8 (evm.TU.Contig381.14) and CKX7 (evm.TU.Contig96.52) were significantly downregulated. The significant expression of hormone-related genes indicates that aluminum stress affects $N$. cadamba root growth via regulating the transcription of hormones biosynthesis and or signaling-related genes.

\subsection{ROS-Related Genes Respond to Aluminum Stress}

Under low $\mathrm{pH}$ conditions, aluminum stress can increase the level of ROS, causing membrane lipid peroxidation and inducing the expression of genes related to oxidative stress. Aluminum stress significantly increased the expression of OXI1 (evm.TU.Contig421.76) in N. cadamba and Arabidopsis thaliana to mediate oxidative burst. RNA-seq analysis showed that PER and GST family genes were significantly expressed in aluminum stress-induced parameters and oxidative stress response (Figure 11B). This may be the main regulatory factor of oxidative stress induced by aluminum stress. The expression of PER family genes in N. cadamba was significantly downregulated at 1 day, 3 days, and 7 days after aluminum stress, which was consistent with the decreasing trend of POD activity at 3 days and 7 days. The downregulation of PER family and GST family gene expression after aluminum stress indicates that aluminum stress resulted in the reduction of enzyme activity, which led to the increase in $\mathrm{H}_{2} \mathrm{O}_{2}$ content, the decrease of binding ability of glutathione to various electronic compounds, and an increase in ROS content that led to imbalance of metabolic level. However, at the same time, the transcripts of GSTU9 (evm.TU.Contig130.57) were significantly upregulated. It is probable that evm.TU.Contig130.57 is involved in detoxification and antioxidation of osmotic stress caused by ROS in order to avoid adverse effects of aluminum stress on N. cadamba growth.

\section{Discussion}

In this study, hydroponic culture was used to study the effects of $\mathrm{AlCl}_{3}$ treatment on N. cadamba in acidic environment ( $\mathrm{pH} 4.5$ ) with simple calcium solution. We revealed the responses of N. cadamba to aluminum stress at the physiological and molecular levels through an RNA-seq approach. Numberous DEGs have been uncovered when subjected to $\mathrm{Al}$ stress in N. cadamba roots at different time points. Our results provide useful cues to plant biologists.

In line with previous studies, the most rapid and obvious effect of aluminum stress on N. cadamba is the inhibition of root growth (Figure 1A). Our results are consistent with the phenotype of Gramineae plants, but they have a significant concentration difference and action time difference with Gramineae plants. As reported, the inhibition rate of root elongation of japonica rice variety (Koshihikari) reached $42 \%$ after being treated with $50 \mu \mathrm{M}$ aluminum for $24 \mathrm{~h}$, while that of indica rice variety (Kasalath) reached 73\% [82]. The root elongation of wheat line Atlas66 (aluminum-tolerant genotype) decreased from $57.5 \%$ to $18.71 \%$ with an increase of aluminum concentration from $50 \mu \mathrm{M}$ to $100 \mu \mathrm{M}$, and that of EM12 (the main fine variety in China) decreased from 30.09\% to 3.09\%. The change of Scout66 (aluminum sensitive genotype) decreased from $19.02 \%$ to $0.97 \%$ [83], while in Solanaceae, $700 \mathrm{mM} \mathrm{AlCl}_{3}$ significantly decreased the relative root growth of Actinidia chinensis Planch without time dependency [84], and 250-500 $\mathrm{mM} \mathrm{AlCl}_{3}$ treatment significantly inhibited the growth of lateral roots of chickpea. Moreover, the rooting pattern was affected by $\mathrm{AlCl}_{3}$ concentration gradient [85]. 
Interestingly, $50 \mu \mathrm{M} \mathrm{AlCl}_{3}$ had a certain promoting effect on the root growth, while $100 \mu \mathrm{M}, 200 \mu \mathrm{M}$, and $400 \mu \mathrm{M} \mathrm{AlCl}_{3}$ concentrations inhibited the root elongation and root morphology of N. cadamba, and the inhibitory effect was more significant with the increase of concentration.

Aluminum stress induced the expression of the XTH gene family with tissue specificity by targeting the cell wall. OsXTH1 is only expressed in rice roots, but AtXTH1 is expressed in anthers tissue of Arabidopsis [35,86]. AtXTH26 is specifically expressed in roots [87], AtXTH32 is specifically expressed in stems. The XTH family genes in N. cadamba mainly showed the downregulation of XTH1, XTH8, XTH32, and XTH26 in the root tip to deal with aluminum stress. There are obvious differences between Arabidopsis thaliana and rice, so it is necessary to further determine the XTH in other tissues of N. cadamba.

The interaction of $\mathrm{Al}^{3+}$ with other ions has been revealed [88]. N. cadamba showed obvious differences in element absorption under aluminum stress (Figure 3), including the increase in $\mathrm{Al}$ and the invariance of $\mathrm{K}$. To our surprise, the $\mathrm{K}$ concentration in grasses such as rice, corn, and wheat under aluminum stress changes significantly [88-91]. However, our transcriptome sequencing (RNA-seq) indicates that the expression of $\mathrm{K}$ transporter genes evm.TU.Contig 41.8 and evm.TU.Contig341.538 were significantly upregulated at 1 day, 3 days, and 7 days of aluminum stress, However, the concentration of $\mathrm{K}$ in the root tip did not change, which may be due to the transfer of potassium absorbed by N. cadamba to other parts (Figures $3 \mathrm{H}$ and 10A). This means that although the ion transporters in N. cadamba were significantly affected under aluminum stress, the ion levels were balanced at the same time to ensure normal growth. In this study, aluminum stress generates a very significant change in the levels of cytoplasmic $\mathrm{Al}^{3+}$ and $\mathrm{Ca}^{2+}$ in the root system. We found that a large amount of $\mathrm{Al}^{3+}$ absorbed by the root tip was found to be mainly distributed in the root tip (Figure $3 \mathrm{~A}$ ). This indicates that N. cadamba copes with $\mathrm{Al}$ stress through exclusion of $\mathrm{Al}$ in cell wall. Additionally, the concentrations of $\mathrm{Mg}$ and $\mathrm{Mn}$ in the root tip of N. cadamba decreased significantly after 1 day and 3 days of aluminum stress, but there was no significant change compared with the control at 7 days, which may be due to the absorption of self-regulating elements after adaptation to aluminum stress. At the same time, the downregulation of evm.TU.Contig16.298 by aluminum stress may also be one of the reasons for the significant decrease of magnesium concentration, which is consistent with previous study [89]. Thus, it is suggested that $\mathrm{Al}^{3+}$ may potentially compete with other ions for enzyme binding sites and interfere with the absorption, migration, and utilization of other elements, thus affecting the nutritional imbalance at the overall plant level or in individual cells.

In addition to the element absorption, the tissue-specific changes caused by $\mathrm{Al}$ stress that change the cell membrane are also reflected in the activities of related enzymes that quench ROS. Past studies on wheat indicate that Al stress increases the activities of SOD and CAT enzymes [92], but both of them are inhibited in microalgae Scenedesmus spp. [56]. In addition, in this study, aluminum stress boosts the activities of SOD, CAT, and POD in the root tip of N. cadamba, while the content of MDA decreased. Surprisingly, MDA, which is one of the indicators of ROS content, increased in rice under aluminum stress [20]. This means that there are differences and similarities in the change trend of ROS in different plants under aluminum stress. In addition, changes of ROS content in leaves and roots also indicated that there are certain differences among different tissues.

Under acidic conditions, the growth and development of N. cadamba was limited by aluminum stress (Figure 2), which was closely related to the imbalance of hormone expression, the decrease of cell wall malleability, the damage of the cell membrane, and the expression regulation of genes related to ROS changes. RNA-seq analysis showed that $N$. cadamba mainly promoted the expression of ethylene regulatory genes, inhibited the expression of auxin-related genes, and then regulated the expression of ROS and lignin-related genes in response to aluminum stress. At the same time, the action of $\mathrm{Al}^{3+}$ on the cell membrane limits the absorption, transport, and utilization of other elements, which also induces changes in the activity of related ion transporters, further regulating and supplementing the necessary element balance for plant growth. In addition, a large number of $\mathrm{Al}^{3+}$ ions can induce the expression of related protein kinase-regulated genes, and then make the corresponding transcription 
factors respond to aluminum stress by regulating the expression of organic acid secretion-related transporter genes or ROS and lignin monomer synthase-related genes. We summarize the possible molecular regulatory mechanisms in Figure 12. However, we also found that some new genes or functional unknown genes were significantly expressed after aluminum stress (Table S5); the specific mechanism of these novel genes requires further exploration.

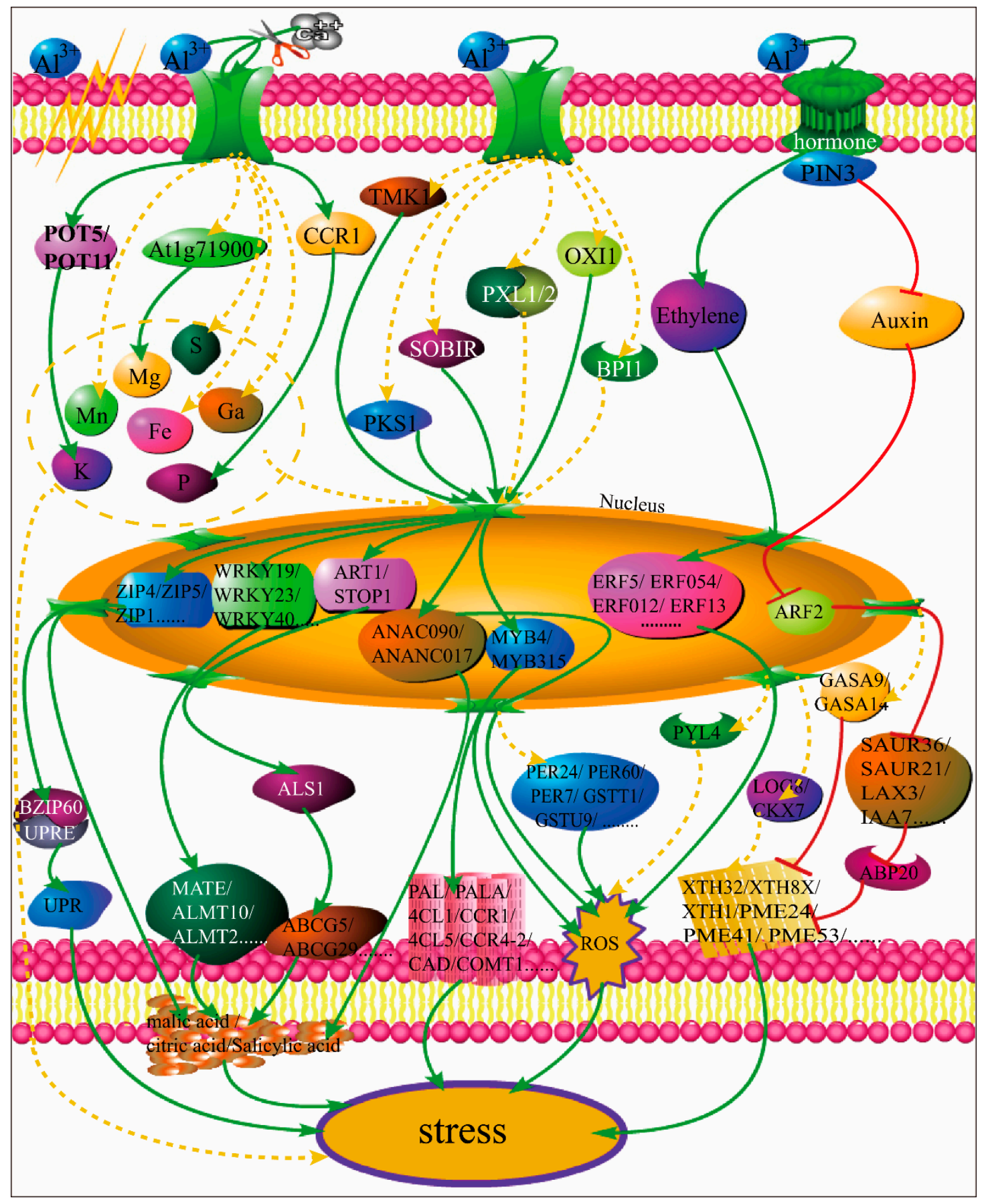

Figure 12. Aluminum stress pathway diagram at the cell level in N. cadamba. The green solid line indicates that the upstream gene regulation activates the downstream gene, the red solid line indicates that the upstream gene regulation suppresses the downstream gene, and the yellow dotted line indicates that the upstream gene indirectly or possibly regulates the downstream gene and responds to stress response. 


\section{Materials and Methods}

\subsection{Materials}

Using the existing tissue culture seedlings of N. cadamba in State Key Laboratory for Conservation and Utilization of Subtropical Agro-Bioresources, the excellent single strain was selected for tissue culture and propagation, and the tissue culture seedlings with the same growth state were selected as experimental materials for aluminum stress water culture treatment.

\subsection{Seedling Culture}

At about 15 day (d) of tissue culture seedlings were domesticated for 4-7 days, and the seedlings with plant height of about $4-5 \mathrm{~cm}$ were cultured in water in the greenhouse with light of 5000 luxe and room temperature of $25^{\circ} \mathrm{C}$, with a light/dark cycle of $13 \mathrm{~h} / 11 \mathrm{~h}$. First, cultured in water for 6-8 days, then incubated in Hoagland solution [93] for 3-4 days, then cultured in deionized water for 3 days. Then the uniform seedlings were transferred into aluminum-containing nutrient solutions ( $\mathrm{pH} 4.5$ ) supplemented with calcium $\left(\mathrm{CaCl}_{2} 0.5 \mathrm{mM}\right)$. The nutrient solution was changed every 3 days, oxygen pump was added to each culture box. The samples were sampled as described, and the related physiological and molecular parameters were determined as described.

\subsection{Experimental Design}

In order to screen the most obvious phenotype of $N$. cadamba under aluminum stress, five $\mathrm{AlCl}_{3}$ concentration gradients were set under the acidic condition of $\mathrm{pH} 4.5$, which were $0 \mu \mathrm{M} / \mathrm{L}, 50 \mu \mathrm{M} / \mathrm{L}$, $100 \mu \mathrm{M} / \mathrm{L}, 200 \mu \mathrm{M} / \mathrm{L}$, and $400 \mu \mathrm{M} / \mathrm{L}$. Each biological repeat contained five technical repeats. Test statistics were conducted and materials were collected at the same time every day. According to the needs of the experiment, the collected samples were quickly cryopreserved in liquid nitrogen or tested directly. The treatment concentration with the greatest phenotypic difference was selected as the working concentration to do further experiments according to the regular statistics of plant height and root length.

\subsection{Determination of Biomass}

The dry weight was determined, and the materials were collected at 0 days and 7 days, respectively, and then dried at $65{ }^{\circ} \mathrm{C}$ (Oven, DEPU, China). The effects of aluminum stress on the biomass of $N$. cadamba were expressed by the percentage of aboveground dry weight (ADW)/total plant dry weight (TDW) and belowground dry weight (UDW)/total plant dry weight (TDW), respectively.

\subsection{Observation on Lignification of Root and Stem}

The effects of aluminum stress on the xylem of N. cadamba were determined. The third stem node (from top to bottom) and $1 \mathrm{~cm}$ root tip of $N$. cadamba in the treatment group and control group were used as experimental materials at $18 \mathrm{~d}$. After embedded in 3\% agarose (Biowest, BY-R0100, Spain), the thickness of cross section of stem node was adjusted to $45 \mu \mathrm{m}$, the thickness of root cross section was set to $80 \mu \mathrm{m}$ (vibratome, LeicaVT1000S, Leica Microsystems, Buffalo Grove, IL, USA). Specimens were stained with $0.01 \%$ toluidine blue [94] and photos were taken with automatic digital scanning imaging system.

\subsection{Determination of Root Growth}

The root growth after aluminum stress was determined. The whole root system was scanned with WinRHIZO at different time periods (Scanning device LC4800-II, Canada), and then statistical analysis was carried out. 


\subsection{Absorption and Distribution of Aluminum by Root Tip}

Eriochrome cyanine $\mathrm{R}$ as a chromogenic agent of aluminum, has stability and selectivity, and can form a red-blue complex with aluminum under neutral conditions [95], so the root tips of 1-2 cm cut and treated for different times are cleaned with pure water for $0.5 \mathrm{~h}$, then stained with $0.1 \%$ Eriochrome cyanine R solution for $0.5 \mathrm{~h}$, and finally washed with pure water for $0.5 \mathrm{~h}$, observed and photographed under a microscope (XSp-36-1600X-LED, Phoenix, China).

\subsection{Determination of Chlorophyll}

According to the absorption of visible spectrum by chloroplast pigment extract, the extinction of chloroplast pigment was determined by spectrophotometer (UV-1200, MAPADA, China) at a specific wavelength. First, $50 \mathrm{mg}$ of fresh leaves was taken with a punch (except the main veins), then $95 \%$ ethanol was added to fix the volume to $5 \mathrm{~mL}$, and the chlorophyll was extracted by shaking. The extracted solution was collected and diluted at a ratio of 1:1, and the extinction was determined at the wavelengths of $470 \mathrm{~nm}, 649 \mathrm{~nm}$, and $665 \mathrm{~nm}$. The content of chlorophyll is calculated according to the following formula.

$$
\begin{aligned}
& \text { Chlorophyll content }(\mathrm{mg} / \mathrm{g})=\frac{(\text { concentration } \times \text { extract volume } \times \text { dilution multiple })}{\text { fresh weight of the sample }} \\
& \text { Chla }=13.95 \mathrm{D} 665-6.88 \mathrm{D} 649 \\
& \mathrm{Chlb}=24.96 \mathrm{D} 649-7.32 \mathrm{D} 665 \\
& \mathrm{Cx.c}=\frac{1000 \mathrm{D} 470-2.05 \mathrm{Ca}-114.8 \mathrm{Cb}}{245}
\end{aligned}
$$

Unit: $\mathrm{mg} / \mathrm{L}$

The concentration of Chla and Chlb represent chlorophyll A and B in the formula, respectively; the total concentration of Cx.c represents total carotenoids; and D470, D649, and D665 were chloroplast pigment extract under an extinction wavelength of $470 \mathrm{~nm}, 649 \mathrm{~nm}$, and $665 \mathrm{~nm}$, respectively.

\subsection{Determination of ROS in Leaves and Roots}

According to the ratio of tissue quality (g): extract volume (ml) 1:5-10, the fresh weight of leaf and root tip was $0.1 \mathrm{~g}$, respectively. After centrifugation with phosphate buffer solution of $\mathrm{pH}=7.0$ at $4{ }^{\circ} \mathrm{C}$, the supernatant was taken as the follow-up determination sample. Each set of 3 biological repeats contained 5 technical repeats. SOD, CAT, POD, and MDA were determined (Suzhou Keming Biotechnology Co., Ltd. kit) by Microplate reader (Multiskan FC, Thermo fisher scientific, Waltham, MA, USA). The protein concentration was determined (the BCA method) by Microplate reader (Multiskan FC, Thermo fisher scientific, Waltham, MA, USA).

\subsection{Determination of Element Concentration in Root Tip}

The changes of element concentrations in root tips at different time points after aluminum stress were determined. Root tip samples were collected at different time points under aluminum stress, dried at $65{ }^{\circ} \mathrm{C}$, and then ground and weighed $0.1 \mathrm{~g}$ samples were digested by STARTD microwave digestion system (SN131825, Milestoone, Milan, Italy). The microwave digestion tube was added together with $5 \mathrm{~mL} \mathrm{HNO}_{3}$ and $2 \mathrm{~mL} 30 \% \mathrm{H}_{2} \mathrm{O}_{2}$, and the temperature was raised to $130{ }^{\circ} \mathrm{C}$ in $10 \mathrm{~min}$, kept at $130{ }^{\circ} \mathrm{C}$ for $10 \mathrm{~min}$, increased to $180^{\circ} \mathrm{C}$ within $6 \mathrm{~min}$, kept at $180^{\circ} \mathrm{C}$ for $30 \mathrm{~min}$, and finally cooled down $30 \mathrm{~min}$ in the fume cupboard. After microwave digestion, the mixture was moved to a volumetric flask and fixed volume to $50 \mathrm{~mL}$, then filtered with quantitative filter paper. After the filtered reactants were diluted 100 times, the concentrations of $\mathrm{Mn}, \mathrm{Fe}, \mathrm{Ca}, \mathrm{Mg}$, and $\mathrm{K}$ were determined by atomic absorption 
spectrometer, and the concentrations of $\mathrm{Al}, \mathrm{P}$, and $\mathrm{S}$ were determined by inductively coupled plasma atomic emission spectrometer (ICP-AES, AIRIS/AP, TJA, Thermo). The calculation formula is

$$
\text { Element concentration }=\frac{(\text { Csample }-\mathrm{Cck}) \mathrm{mg} / \mathrm{L} \times 50 \mathrm{~mL} \times \text { dilution multiple }}{\text { dry weight } \mathrm{g}}
$$

Unit: $\mu \mathrm{g} / \mathrm{g}, \mathrm{mg} / \mathrm{g}$

\subsection{Construction of Sequencing Library}

In this study, total RNA was extracted from 1-2 cm root tips of $\mathrm{N}$. cadamba treated with $0 \mu \mathrm{M}$ and $+\mathrm{Al}$ for 0 days, 1 day, 3 days, and 7 days, and a sequencing library was constructed after qualified detection. A total of 21 libraries (AL0_1, AL0_2, AL0_3, AL1_CK_1, AL1_CK_2, AL1_CK_3, AL1_400_1, AL1_400_2, AL1_400_3, AL3_CK_1, AL3_CK_2, AL3_CK_3, AL3_400_1, AL3_400_2, AL3_400_3, AL7_CK_1, AL7_CK_2, AL7_CK_3, AL7_400_1, AL7_400_2, and AL7_400_3) was constructed with samples from four periods, in which there were three biological repeats in the treatment group and the control group in each period, then further horizontal and vertical analysis. The original sequence (Sequenced Reads) is called clean reads after filtering by Raw reads. The tissue samples of 1-2 cm root tip of N.cadamba were collected at different time after aluminum treatment. After quick freezing with liquid nitrogen. RNA, was extracted by Magen (HiPure HP Plant RNA Mini Kit) kit, and then combined with RNA-seq sequencing technology to determine the differentially expressed genes in the root tip of N.cadamba after aluminum treatment. The library and sequencing were completed by Nuohe Zhiyuan Bioinformation Technology Co., Ltd. NovoMagic (https://magic.novogene.com/customer/main\#/login). TBTools [96] were used for differential gene expression analysis and differential gene enrichment analysis. RNA-seq data were submitted to https://bigd.big.ac.cn/gsub/and the submission number was CRA003281.

\subsection{2. $q R T-P C R$}

Use TaKaRa PrimeScript ${ }^{\mathrm{TM}}$ RT reagent Kit with gDNA Eraser (Perfect Real Time, Takara, Japan) to synthesize cDNA from the sequenced RNA samples and perform real-time fluorescent quantitative PCR (qRT-PCR) on a LightCycler 480 instrument. The reaction program is $95^{\circ} \mathrm{C}, 3 \mathrm{~s} ; 95^{\circ} \mathrm{C}, 5 \mathrm{~s}, 40$ cycles; $60^{\circ} \mathrm{C}$, 30s [97]. The primers used to determine the transcripts of genes are shown in Supplementary Table S3. The reference gene was N. cadamba SAMDC [98]. Results were from three biological replicates with 4 technical replicates. Using OriginPro 9.1 64Bit software, the relative gene expression was calculated by the $2^{-\Delta \Delta \mathrm{Ct}}$ method [99].

\section{Conclusions}

The results showed that aluminum stress mainly affected the growth and development of $N$. cadamba roots. The $\mathrm{Al}^{3+}$ absorbed by the root was preferentially deposited in the root tip, and then transferred to the upper part to influence the xylem thickening of the stem and the decrease of chlorophyll content in leaves. A large amount of $\mathrm{Al}^{3+}$ transfer will affect the absorption of other elements and upregulate the expression of related ion transporters, resulting in the disorder of element absorption mechanism and root nutrition imbalance. When $\mathrm{Al}^{3+}$ acted on the cell membrane, the imbalance of ROS level was induced, while ROS as a signal molecule triggered hormone changes and then induced the significant expression of related transcription factor genes. Furthermore, ROS regulate the expression of ALMT, MATE, and ABC transporter family genes, and the aluminum transporter AtALS1 upregulated the expression of similar genes significantly and promoted the secretion of organic acids or accumulated $\mathrm{dAL}^{3+}$ in vacuoles to form a detoxification mechanism in response to aluminum stress. 
Supplementary Materials: Supplementary Data for this article are available at http://www.mdpi.com/1422-0067/ 21/24/9624/s1 (International Journal of Molecular Sciences) Online. Figure S1. Pearson correlation between samples; Figure S2. Volcanic map of differentially expressed gene (DEGs); Figure S3. GO enrichment of three comparative combinations of aluminum stress in different periods; Figure S4. Trend clustering of DEGs; Figure S5. Heat map of DEGs expression in response to aluminum stress in various periods; Table S1. Quality evaluation of sequencing data; Table S2. Statistics on the alignment of lean reads and reference genomes; Table S3. Primer pairs used to verify gene fluorescence quantification; Table S4. High expression of transporters-encoding and protein kinases encoding genes; Table S5. New DEGs and unnamed DEGs.

Author Contributions: B.D. had the main responsibility for data collection, analysis, and writing. C.C. and Y.L. assisted in the research. L.L., M.F.Q., J.W. and H.L. contributed to the interpretation of data and manuscript preparation. A.-M.W. (the corresponding author) had the overall responsibility for experimental design and project management. All authors have read and agreed to the published version of the manuscript.

Funding: This research received no external funding.

Acknowledgments: Financial support for this work was obtained by Key Project of Guangzhou Science and Technology Plan (201904020014), China and the National Natural Science Foundation of China (Grant Numbers (31870653, 31670670, 31811530009, 31670601).

Conflicts of Interest: The authors declare no conflict of interest.

\section{Abbreviations}

$\begin{array}{ll}\text { SOD } & \text { Superoxide dismutase } \\ \text { CAT } & \text { Catalase from micrococcus lysodeiktic } \\ \text { POD } & \text { Peroxidase } \\ \text { DEGS } & \text { Differential expression genes } \\ \text { DTZ } & \text { Distal transition zone of the root } \\ \text { ROS } & \text { Reactive oxygen species } \\ \text { PR } & \text { Primary root } \\ \text { Xylan endoglucanase/hydrolase } & \text { XTH } \\ \text { Xylan endoglucanase } & \text { XET } \\ \text { PME } & \text { Pectin methyl esterase } \\ \text { PAL } & \text { Phenylalanine ammonia-lyase } \\ 4 \text { CL } & \text { 4-coumarate: coa ligase } \\ \text { CCR } & \text { Cinnamoyl-coa reductase } \\ \text { COMT } & \text { Caffeic acid o-methyltransferase } \\ \text { CAD } & \text { Cinnamyl alcohol dehydrogenase } \\ \text { KEGG } & \text { Kyoto Encyclopedia of Genes and Genomes }\end{array}$

\section{References}

1. Schmitt, M.; Watanabe, T.; Jansen, S. The effects of aluminium on plant growth in a temperate and deciduous aluminium accumulating species. AoB PLANTS 2016, 8, 8. [CrossRef]

2. Hoekenga, O.A.; Vision, T.J.; Shaff, J.E.; Monforte, A.J.; Lee, G.P.; Howell, S.H.; Kochian, L.V. Identification and characterization of aluminum tolerance loci in Arabidopsis (Landsberg erecta x Columbia) by quantitative trait locus mapping. A physiologically simple but genetically complex trait. Plant Physiol. 2003, 132, 936-948. [CrossRef] [PubMed]

3. Von Wiren, N. Faculty Opinions Recommendation of Plasma Membrane-Localized Transporter for Aluminum in Rice. Proc. Natl. Acad. Sci. USA 2010, 107, 18381-18385.

4. Samac, D.A.; Tesfaye, M. Plant improvement for tolerance to aluminum in acid soils-A review. Plant Cell Tissue Organ Cult. (PCTOC) 2003, 75, 189-207. [CrossRef]

5. Huynh, V.-B.; Repellin, A.; Zuily-Fodil, Y.; Pham-Thi, A.-T. Aluminum stress response in rice: Effects on membrane lipid composition and expression of lipid biosynthesis genes. Physiol. Plant. 2012, 146, 272-284. [CrossRef] [PubMed]

6. Guo, T.R.; Yao, P.-C.; Zhang, Z.-D.; Wang, J.-J.; Wang, M. Involvement of Antioxidative Defense System in Rice Seedlings Exposed to Aluminum Toxicity and Phosphorus Deficiency. Rice Sci. 2012, 19, 207-212. [CrossRef] 
7. Ryan, P.R.; Delhaize, E.; Jones, D.L. Function and mechanism of organic anion exudation from plant roots. Ann. Rev. Plant Physiol. Plant Mol. Biol. 2001, 52, 527-560. [CrossRef]

8. Kopittke, P.M.; Moore, K.L.; Lombi, E.; Gianoncelli, A.; Ferguson, B.J.; Blamey, F.P.C.; Menzies, N.W.; Nicholson, T.M.; McKenna, B.A.; Wang, P.; et al. Identification of the Primary Lesion of Toxic Aluminum in Plant Roots. Plant Physiol. 2015, 167, 1402-1411. [CrossRef]

9. Liu, C.; Liu, Y.; Wang, S.; Ke, Q.; Yin, L.; Deng, X.; Feng, B. Arabidopsis mgd mutants with reduced monogalactosyldiacylglycerol contents are hypersensitive to aluminium stress. Ecotoxicol. Environ. Saf. 2020, 203, 110999. [CrossRef]

10. Kollmeier, M.; Felle, H.H.; Horst, W.J. Genotypical Differences in Aluminum Resistance of Maize Are Expressed in the Distal Part of the Transition Zone. Is Reduced Basipetal Auxin Flow Involved in Inhibition of Root Elongation by Aluminum? Plant Physiol. 2000, 122, 945-956. [CrossRef]

11. Baluška, F.; Volkmann, D.; Barlow, P.W. A Polarity Crossroad in the Transition Growth Zone of Maize Root Apices: Cytoskeletal and Developmental Implications. J. Plant Growth Regul. 2001, 20, 170-181. [CrossRef]

12. Ma, J.F.; Shen, R.; Nagao, S.; Tanimoto, E. Aluminum Targets Elongating Cells by Reducing Cell Wall Extensibility in Wheat Roots. Plant Cell Physiol. 2004, 45, 583-589. [CrossRef] [PubMed]

13. Matsumoto, H. Cell biology of aluminum toxicity and tolerance in higher plants. Adv. Clin. Chem. 2000, 200, 1-46. [CrossRef]

14. Silva, I.R.; Smyth, T.J.; Moxley, D.F.; Carter, T.E.; Allen, N.S.; Rufty, T.W. Aluminum Accumulation at Nuclei of Cells in the Root Tip. Fluorescence Detection Using Lumogallion and Confocal Laser Scanning Microscopy. Plant Physiol. 2000, 123, 543-552. [CrossRef] [PubMed]

15. Liu, K.; Luan, S. Internal aluminum block of plant inward K+ channels. Plant. Cell 2001, 13, 1453-1465. [CrossRef] [PubMed]

16. Boscolo, P.R.S.; Menossi, M.; Jorge, R.A. Aluminum-induced oxidative stress in maize. Phytochemistry 2003, 62, 181-189. [CrossRef]

17. Yamamoto, Y.; Kobayashi, Y.; Devi, S.R.; Rikiishi, S.; Matsumoto, H. Oxidative stress triggered by aluminum in plant roots. Roots Dyn. Interface Plants Earth 2003, 255, 239-243. [CrossRef]

18. Rengel, Z.; Zhang, W.-H. Role of dynamics of intracellular calcium in aluminium-toxicity syndrome. New Phytol. 2003, 159, 295-314. [CrossRef]

19. Yang, J.L.; Zhu, X.F.; Peng, Y.X.; Zheng, C.; Ming, F.; Zheng, S.J. Aluminum regulates oxalate secretion and plasma membrane H+-ATPase activity independently in tomato roots. Planta 2011, 234, 281-291. [CrossRef]

20. Sharma, P.; Dubey, R.S. Involvement of oxidative stress and role of antioxidative defense system in growing rice seedlings exposed to toxic concentrations of aluminum. Plant Cell Rep. 2007, 26, 2027-2038. [CrossRef]

21. Ali, B.; Hasan, S.; Hayat, S.; Hayat, Q.; Yadav, S.; Fariduddin, Q.; Ahmad, A. A role for brassinosteroids in the amelioration of aluminium stress through antioxidant system in mung bean (Vigna radiata L. Wilczek). Environ. Exp. Bot. 2008, 62, 153-159. [CrossRef]

22. Panda, S.K.; Sahoo, L.; Katsuhara, M.; Matsumoto, H. Overexpression of Alternative Oxidase Gene Confers Aluminum Tolerance by Altering the Respiratory Capacity and the Response to Oxidative Stress in Tobacco Cells. Mol. Biotechnol. 2012, 54, 551-563. [CrossRef] [PubMed]

23. Aghaee, A.; Moradi, F.; Zare-Maivan, H.; Zarinkamar, F.; Irandoost, H.P.; Sharifi, P. Physiological responses of two rice (Oryza sativa L.) genotypes to chilling stress at seedling stage. Afr. J. Biotechnol. 2011, 10, 7617-7621.

24. Endo, H.; Ose, K.; Bai, J.; Imahori, Y. Effect of hot water treatment on chilling injury incidence and antioxidative responses of mature green mume (Prunus mume) fruit during low temperature storage. Sci. Hortic. 2019, 246, 550-556. [CrossRef]

25. Singh, S.; Tripathi, D.K.; Singh, S.; Sharma, S.; Dubey, N.K.; Chauhan, D.K.; Vaculík, M. Toxicity of aluminium on various levels of plant cells and organism: A review. Environ. Exp. Bot. 2017, 137, 177-193. [CrossRef]

26. Yang, J.L.; Li, Y.Y.; Zhang, Y.J.; Zhang, S.S.; Wu, Y.R.; Wu, P.; Zheng, S.J. Cell Wall Polysaccharides Are Specifically Involved in the Exclusion of Aluminum from the Rice Root Apex. Plant Physiol. 2007, 146, 602-611. [CrossRef]

27. Li, X.; Li, Y.; Qu, M.; Xiao, H.; Feng, Y.; Liu, J.; Wu, L.; Yu, M. Cell Wall Pectin and its Methyl-esterification in Transition Zone Determine Al Resistance in Cultivars of Pea (Pisum sativum). Front. Plant Sci. 2016, 7, 7. [CrossRef]

28. Doblin, M.S.; Pettolino, F.; Bacic, A. Plant cell walls: The skeleton of the plant world. Funct. Plant Biol. 2010, 37, 357-381. [CrossRef] 
29. Sasidharan, R.; Voesenek, L.A.; Pierik, R. Cell Wall Modifying Proteins Mediate Plant Acclimatization to Biotic and Abiotic Stresses. Crit. Rev. Plant Sci. 2011, 30, 548-562. [CrossRef]

30. Lampugnani, E.R.; Khan, G.A.; Somssich, M.; Persson, S. Building a plant cell wall at a glance. J. Cell Sci. 2018, 131, jcs207373. [CrossRef]

31. Tabuchi, A.; Matsumoto, H. Changes in cell-wall properties of wheat (Triticum aestivum ) roots during aluminum-induced growth inhibition. Physiol. Plant. 2001, 112, 353-358. [CrossRef]

32. Merino-Gergichevich, C.; Alberdi, M.; Ivanov, A.G.; Reyes-Diaz, M. Al3+-Ca2+ Interaction in Plants Growing in Acid Soils: Al-Phytotoxicity Response to Calcareous Amendments. J. Soil. Sci. Plant. Nutr. 2010, 10, 217-243.

33. Rose, J.K.; Braam, J.; Fry, S.C.; Nishitani, K. The XTH Family of Enzymes Involved in Xyloglucan Endotransglucosylation and Endohydrolysis: Current Perspectives and a New Unifying Nomenclature. Plant Cell Physiol. 2002, 43, 1421-1435. [CrossRef] [PubMed]

34. Zenko, C.; Yokoyama, R.; Nishitani, K.; Kamisaka, S. Effect of hypergravity stimulus on XTH gene expression in Arabidopsis thaliana. Uchu Seibutsu Kagaku 2004, 18, 162-163. [PubMed]

35. Becnel, J.; Natarajan, M.; Kipp, A.; Braam, J. Developmental Expression Patterns of Arabidopsis XTH Genes Reported by Transgenes and Genevestigator. Plant Mol. Biol. 2006, 61, 451-467. [CrossRef] [PubMed]

36. Yu, H.; Guo, J.; Li, Q.; Zhang, X.; Huang, H.; Huang, F.; Yang, A.; Li, T. Characteristics of cadmium immobilization in the cell wall of root in a cadmium-safe rice line (Oryza sativa L.). Chemosphere 2020, 241, 125095. [CrossRef]

37. Zhang, P.; Wang, H.; Qin, X.; Chen, K.; Zhao, J.; Zhao, Y.; Yue, B. Genome-wide identification, phylogeny and expression analysis of the PME and PMEI gene families in maize. Sci. Rep. 2019, 9, 1-12. [CrossRef]

38. Huang, C.F.; Yamaji, N.; Mitani, N.; Yano, M.; Nagamura, Y.; Ma, J.F. A Bacterial-Type ABC Transporter Is Involved in Aluminum Tolerance in Rice. Plant Cell 2009, 21, 655-667. [CrossRef]

39. Vázquez, M.D.; Poschenrieder, C.; Corrales, I.; Barceló, J. Change in Apoplastic Aluminum during the Initial Growth Response to Aluminum by Roots of a Tolerant Maize Variety. Plant Physiol. 1999, 119, 435-444. [CrossRef]

40. Wang, J.-P.; Raman, H.; Zhang, G.-P.; Mendham, N.; Zhou, M. Aluminium tolerance in barley (Hordeum vulgare L.): Physiological mechanisms, genetics and screening methods. J. Zhejiang Univ. Sci. B 2006, 7, 769-787. [CrossRef]

41. Vanholme, R.; Demedts, B.; Morreel, K.; Ralph, J.; Boerjan, W. Lignin Biosynthesis and Structure. Plant Physiol. 2010, 153, 895-905. [CrossRef]

42. Kochian, L.V.; Piñeros, M.A.; Hoekenga, O.A. The Physiology, Genetics and Molecular Biology of Plant Aluminum Resistance and Toxicity. Selenium Plants 2005, 274, 175-195. [CrossRef]

43. Poschenrieder, C.; Gunsé, B.; Corrales, I.; Barceló, J. A glance into aluminum toxicity and resistance in plants. Sci. Total. Environ. 2008, 400, 356-368. [CrossRef]

44. Snedden, W.A.; Fromm, H. Calmodulin as a versatile calcium signal transducer in plants. New Phytol. 2001, 151, 35-66. [CrossRef]

45. Luan, S.; Kudla, J.; Rodriguez-Concepcion, M.; Yalovsky, S.; Gruissem, W. Calmodulins and calcineurin B-like proteins: Calcium sensors for specific signal response coupling in plants. Plant. Cell 2002, 14, S389-S400. [CrossRef]

46. Ohta, M.; Matsui, K.; Hiratsu, K.; Shinshi, H.; Ohme-Takagi, M. Repression domains of class II ERF transcriptional repressors share an essential motif for active repression. Plant. Cell 2001, 13, 1959-1968. [CrossRef]

47. Phukan, U.J.; Jeena, G.S.; Shukla, R.K. WRKY Transcription Factors: Molecular Regulation and Stress Responses in Plants. Front. Plant Sci. 2016, 7, 760. [CrossRef]

48. Zanetti, M.E.; Rípodas, C.; Niebel, A. Plant NF-Y transcription factors: Key players in plant-microbe interactions, root development and adaptation to stress. Biochim. Biophys. Acta (BBA)—Bioenerg. 2017, 1860, 645-654. [CrossRef]

49. Noman, A.; Liu, Z.; Aqeel, M.; Zainab, M.; Khan, M.I.; Hussain, A.; Ashraf, M.F.; Li, X.; Weng, Y.; He, S. Basic leucine zipper domain transcription factors: The vanguards in plant immunity. Biotechnol. Lett. 2017, 39, 1779-1791. [CrossRef]

50. Singh, K.B. Transcription factors in plant defense and stress responses. Curr. Opin. Plant Biol. 2002, 5, 430-436. [CrossRef] 
51. Rentel, M.C.; Lecourieux, D.; Ouaked, F.; Usher, S.L.; Petersen, L.; Okamoto, H.; Knight, H.; Peck, S.C.; Grierson, C.S.; Hirt, H.; et al. OXI1 kinase is necessary for oxidative burst-mediated signalling in Arabidopsis. Nat. Cell Biol. 2004, 427, 858-861. [CrossRef]

52. Wagner, U.; Edwards, R.; Dixon, D.P.; Mauch, F. Probing the Diversity of the Arabidopsis glutathione S-Transferase Gene Family. Plant Mol. Biol. 2002, 49, 515-532. [CrossRef]

53. Wu, H.; Li, L.; Du, J.; Yuan, Y.; Cheng, X.; Ling, H.-Q. Molecular and Biochemical Characterization of the Fe(III) Chelate Reductase Gene Family in Arabidopsis thaliana. Plant Cell Physiol. 2005, 46, 1505-1514. [CrossRef] [PubMed]

54. Liu, N.; You, J.; Shi, W.; Liu, W.; Yang, Z. Salicylic acid involved in the process of aluminum induced citrate exudation in Glycine max L. Plant Soil 2011, 352, 85-97. [CrossRef]

55. Kim, H.J.; Park, J.-H.; Kim, J.; Kim, J.J.; Hong, S.; Kim, J.; Kim, J.H.; Woo, H.R.; Hyeon, C.; Lim, P.O.; et al. Time-evolving genetic networks reveal a NAC troika that negatively regulates leaf senescence in Arabidopsis. Proc. Natl. Acad. Sci. USA 2018, 115, E4930-E4939. [CrossRef] [PubMed]

56. Ameri, M.; Baron-Sola, A.; Khavari-Nejad, R.A.; Soltani, N.; Najafi, F.; Bagheri, A.; Martinez, F.; Hernández, L.E. Aluminium triggers oxidative stress and antioxidant response in the microalgae Scenedesmus sp. J. Plant Physiol. 2020, 153114. [CrossRef]

57. Wang, M.; Qiao, J.; Yu, C.; Chen, H.; Sun, C.; Huang, L.; Li, C.; Geisler, M.; Qian, Q.; Jiang, D.A.; et al. The auxin influx carrier, OsAUX3, regulates rice root development and responses to aluminium stress. Plant Cell Environ. 2019, 42, 1125-1138. [CrossRef]

58. Ganguly, A.; Lee, S.H.; Cho, M.; Lee, O.R.; Yoo, H.; Cho, H.-T. Differential Auxin-Transporting Activities of PIN-FORMED Proteins in Arabidopsis Root Hair Cells. Plant Physiol. 2010, 153, 1046-1061. [CrossRef]

59. López-González, D.; Costas-Gil, A.; Reigosa, M.J.; Araniti, F.; Sánchez-Moreiras, A.M. A natural indole alkaloid, norharmane, affects PIN expression patterns and compromises root growth in Arabidopsis thaliana. Plant Physiol. Biochem. 2020, 151, 378-390. [CrossRef]

60. Wu, D.; Shen, H.; Yokawa, K.; Baluška, F. Alleviation of aluminium-induced cell rigidity by overexpression of OsPIN2 in rice roots. J. Exp. Bot. 2014, 65, 5305-5315. [CrossRef]

61. Wang, C.; Lin, T.; Wang, M.; Qi, X. An AC-Rich Bean Element Serves as an Ethylene-Responsive Element in Arabidopsis. Plants 2020, 9, 1033. [CrossRef]

62. Davletova, S.; Schlauch, K.; Coutu, J.; Mittler, R. The Zinc-Finger Protein Zat12 Plays a Central Role in Reactive Oxygen and Abiotic Stress Signaling in Arabidopsis. Plant Physiol. 2005, 139, 847-856. [CrossRef]

63. Yamaji, N.; Huang, C.F.; Nagao, S.; Yano, M.; Sato, Y.; Nagamura, Y.; Ma, J.F. A Zinc Finger Transcription Factor ART1 Regulates Multiple Genes Implicated in Aluminum Tolerance in Rice. Plant Cell 2009, 21, 3339-3349. [CrossRef] [PubMed]

64. Burr, C.A.; Leslie, M.E.; Orlowski, S.K.; Chen, I.; Wright, C.E.; Daniels, M.J.; Liljegren, S.J. CAST AWAY, a Membrane-Associated Receptor-Like Kinase, Inhibits Organ Abscission in Arabidopsis. Plant Physiol. 2011, 156, 1837-1850. [CrossRef] [PubMed]

65. Ragel, P.; Rodenas, R.; Garcia-Martin, E.; Andres, Z.; Villalta, I.; Nieves-Cordones, M.; Rivero, R.M.; Martinez, V.; Pardo, J.M.; Quintero, F.J.; et al. The CBL-Interacting Protein Kinase CIPK23 Regulates HAK5-Mediated High-Affinity K+ Uptake in Arabidopsis Roots. Plant Physiol. 2015, 169, 2863-2873. [PubMed]

66. Martinoia, E. Faculty Opinions recommendation of A gene in the multidrug and toxic compound extrusion (MATE) family confers aluminum tolerance in sorghum. Nat. Genet. 2007, 39, 1156-1161. [CrossRef]

67. Eticha, D.; Zahn, M.; Bremer, M.; Yang, Z.; Rangel, A.F.; Rao, I.M.; Horst, W.J. Transcriptomic analysis reveals differential gene expression in response to aluminium in common bean (Phaseolus vulgaris) genotypes. Ann. Bot. 2010, 105, 1119-1128. [CrossRef] [PubMed]

68. Ma, J.F. Role of Organic Acids in Detoxification of Aluminum in Higher Plants. Plant Cell Physiol. 2000, 41, 383-390. [CrossRef] [PubMed]

69. Ding, Z.J.; Yan, J.Y.; Xu, X.Y.; Li, G.X.; Zheng, S.J. WRKY46 functions as a transcriptional repressor ofALMT1, regulating aluminum-induced malate secretion in Arabidopsis. Plant J. 2013, 76, 825-835. [CrossRef]

70. Melo, J.O.; Martins, L.G.C.; Barros, B.A.; Pimenta, M.R.; Lana, U.G.P.; Duarte, C.E.M.; Pastina, M.M.; Guimaraes, C.T.; Schaffert, R.E.; Kochian, L.V.; et al. Repeat variants for the SbMATE transporter protect sorghum roots from aluminum toxicity by transcriptional interplay in cis and trans. Proc. Natl. Acad. Sci. USA 2019, 116, 313-318. [CrossRef] 
71. Sasaki, T.; Yamamoto, Y.; Ezaki, B.; Katsuhara, M.; Ahn, S.J.; Ryan, P.R.; Delhaize, E.; Matsumoto, H. A wheat gene encoding an aluminum-activated malate transporter. Plant J. 2004, 37, 645-653. [CrossRef]

72. Wu, D.; Zhao, M.; Shen, S.; Fu, Y.; Sasaki, T.; Yamamoto, Y.; Wei, W.; Shen, H. Al-induced secretion of organic acid, gene expression and root elongation in soybean roots. Acta Physiol. Plant. 2012, 35, 223-232. [CrossRef]

73. Larsen, P.B.; Cancel, J.; Rounds, M.; Ochoa, V. Arabidopsis ALS1 encodes a root tip and stele localized half type $A B C$ transporter required for root growth in an aluminum toxic environment. Planta 2006, 225, 1447-1458. [CrossRef] [PubMed]

74. Larsen, P.B.; Geisler, M.; Jones, C.A.; Williams, K.M.; Cancel, J.D. ALS3 encodes a phloem-localized ABC transporter-like protein that is required for aluminum tolerance in Arabidopsis. Plant J. 2005, 41, 353-363. [CrossRef] [PubMed]

75. Kobayashi, Y.; Hoekenga, O.A.; Itoh, H.; Nakashima, M.; Saito, S.; Shaff, J.E.; Maron, L.G.; Piñeros, M.A.; Kochian, L.V.; Koyama, H. Characterization of AtALMT1 Expression in Aluminum-Inducible Malate Release and Its Role for Rhizotoxic Stress Tolerance in Arabidopsis. Plant Physiol. 2007, 145, 843-852. [CrossRef]

76. Sawaki, Y.; Iuchi, S.; Kobayashi, Y.; Kobayashi, Y.; Ikka, T.; Sakurai, N.; Fujita, M.; Shinozaki, K.; Shibata, D.; Kobayashi, M.; et al. STOP1 Regulates Multiple Genes That Protect Arabidopsis from Proton and Aluminum Toxicities. Plant Physiol. 2009, 150, 281-294. [CrossRef]

77. Gao, W.; Xiao, S.; Li, H.-Y.; Tsao, S.-W.; Chye, M.-L. Arabidopsis thaliana acyl-CoA-binding protein ACBP2 interacts with heavy-metal-binding farnesylated protein AtFP6. New Phytol. 2009, 181, 89-102. [CrossRef]

78. Cowan, G.H.; Roberts, A.G.; Jones, S.; Kumar, P.; Kalyandurg, P.B.; Gil, J.F.; Savenkov, E.I.; Hemsley, P.A.; Torrance, L. Potato Mop-Top Virus Co-Opts the Stress Sensor HIPP26 for Long-Distance Movement. Plant Physiol. 2018, 176, 2052-2070. [CrossRef]

79. He, L.; Wang, C.; Xing, Y.; Zhou, W.; Pian, R.; Yang, F.; Chen, X.; Zhang, Q. Dynamics of proteolysis, protease activity and bacterial community of Neolamarckia cadamba leaves silage and the effects of formic acid and Lactobacillus farciminis. Bioresour. Technol. 2019, 294, 122127. [CrossRef]

80. Wang, Y.; Zhou, W.; Wang, C.; Yang, F.; Chen, X.; Zhang, Q. Effect on the ensilage performance and microbial community of adding Neolamarckia cadamba leaves to corn stalks. Microb. Biotechnol. 2020, 13, 1502-1514. [CrossRef]

81. Guo, J.H.; Liu, X.J.; Zhang, Y.; Shen, J.L.; Han, W.X.; Zhang, W.F.; Christie, P.; Goulding, K.W.T.; Vitousek, P.M.; Zhang, F.S. Significant Acidification in Major Chinese Croplands. Science 2010, 327, 1008-1010. [CrossRef]

82. Famoso, A.N.; Zhao, K.; Clark, R.T.; Tung, C.-W.; Wright, M.H.; Bustamante, C.; Kochian, L.V.; McCouch, S.R. Genetic Architecture of Aluminum Tolerance in Rice (Oryza sativa) Determined through Genome-Wide Association Analysis and QTL Mapping. PLoS Genet. 2011, 7, e1002221. [CrossRef]

83. Li, Y.; Yang, G.X.; Luo, L.T.; Ke, T.; Zhang, J.R.; Li, K.X.; He, G.Y. Aluminium sensitivity and tolerance in model and elite wheat varieties. Cereal Res. Commun. 2008, 36, 257-267. [CrossRef]

84. He, H.; Li, Y.; He, L.-F. Aluminum toxicity and tolerance in Solanaceae plants. South Afr. J. Bot. 2019, 123, 23-29. [CrossRef]

85. Choudhury, S.; Sharma, P. Aluminum stress inhibits root growth and alters physiological and metabolic responses in chickpea (Cicer arietinum L.). Plant Physiol. Biochem. 2014, 85, 63-70. [CrossRef]

86. Yokoyama, R.; Rose, J.K.; Nishitani, K. A Surprising Diversity and Abundance of Xyloglucan Endotransglucosylase/Hydrolases in Rice. Classification and Expression Analysis. Plant Physiol. 2004, 134, 1088-1099. [CrossRef]

87. Yokoyama, R.; Nishitani, K. Endoxyloglucan Transferase is Localized both in the Cell Plate and in the Secretory Pathway Destined for the Apoplast in Tobacco Cells. Plant Cell Physiol. 2001, 42, 292-300. [CrossRef]

88. Silva, S.; Pinto-Carnide, O.; Martins-Lopes, P.; Matos, M.; Guedes-Pinto, H.; Santos, C.V. Differential aluminium changes on nutrient accumulation and root differentiation in an Al sensitive vs. tolerant wheat. Environ. Exp. Bot. 2010, 68, 91-98. [CrossRef]

89. de Mendonca, R.J.; Cambraia, J.; de Oliveira, J.A.; Oliva, M.A. Aluminum effects on the uptake and utilization of macronutrients in two rice cultivars. Pesqui. Agropecu. Bras. 2003, 38, 843-848.

90. Mariano, E.D.; Keltjens, W.G. Long-Term Effects of Aluminum Exposure on Nutrient Uptake by Maize Genotypes Differing in Aluminum Resistance. J. Plant Nutr. 2005, 28, 323-333. [CrossRef]

91. Giannakoula, A.; Moustakas, M.; Mylona, P.; Papadakis, I.; Yupsanis, T. Aluminum tolerance in maize is correlated with increased levels of mineral nutrients, carbohydrates and proline, and decreased levels of lipid peroxidation and Al accumulation. J. Plant Physiol. 2008, 165, 385-396. [CrossRef] 
92. Darko, E.; Ambrus, H.; Stefanovits-Bányai, É.; Fodor, J.; Bakos, F.; Barnabás, B. Aluminium toxicity, $\mathrm{Al}$ tolerance and oxidative stress in an Al-sensitive wheat genotype and in Al-tolerant lines developed by in vitro microspore selection. Plant Sci. 2004, 166, 583-591. [CrossRef]

93. Hoagland, D.R. Minute amounts of chemical elements in relation to plant growth. Science 1940, 91, 557-560. [CrossRef] [PubMed]

94. Zhao, X.; Liu, N.; Shang, N.; Zeng, W.; Ebert, B.; Rautengarten, C.; Zeng, Q.-Y.; Li, H.; Chen, X.; Beahan, C.; et al. Three UDP-xylose transporters participate in xylan biosynthesis by conveying cytosolic UDP-xylose into the Golgi lumen in Arabidopsis. J. Exp. Bot. 2018, 69, 1125-1134. [CrossRef] [PubMed]

95. Buruberri, L.; Tobaldi, D.; Caetano, A.; Seabra, M.; Labrincha, J. Evaluation of reactive Si and Al amounts in various geopolymer precursors by a simple method. J. Build. Eng. 2019, 22, 48-55. [CrossRef]

96. Chen, C.; Chen, H.; Zhang, Y.; Thomas, H.R.; Frank, M.H.; He, Y.; Xia, R. TBtools: An Integrative Toolkit Developed for Interactive Analyses of Big Biological Data. Mol. Plant 2020, 13, 1194-1202. [CrossRef]

97. Qin, W.; Yin, Q.; Chen, J.; Zhao, X.; Yue, F.; He, J.; Yang, L.; Liu, L.; Zeng, Q.; Lu, F.; et al. The class II KNOX transcription factors KNAT3 and KNAT7 synergistically regulate monolignol biosynthesis in Arabidopsis. J. Exp. Bot. 2020, 71, 5469-5483. [CrossRef]

98. Huang, T.; Long, J.; Liu, S.-W.; Yang, Z.-W.; Zhu, Q.-J.; Zhao, X.-L.; Peng, C. Selection and Validation of Reference Genes for mRNA Expression by Quantitative Real-Time PCR Analysis in Neolamarckia cadamba. Sci. Rep. 2018, 8, 1-11. [CrossRef]

99. Pfaffl, M.W. A new mathematical model for relative quantification in real-time RT-PCR. Nucleic Acids Res. 2001, 29, e45. [CrossRef]

Publisher's Note: MDPI stays neutral with regard to jurisdictional claims in published maps and institutional affiliations. 